\title{
Direct-ink writing of strong and biocompatible titanium scaffolds with bimodal interconnected porosity
}

Published in Additive Manufacturing (2021), vol.39, 101859

https://doi.org/10.1016/j.addma.2021.101859

M.Coffigniez, L.Gremillard, S.Balvay, J.Lachambre, J.Adrien, X.Boulnat*

Univ. Lyon, INSA Lyon, MATEIS, UMR CNRS 5510, F69621Villeurbanne, France

* Corresponding author : Xavier.boulnat@insa-lyon.fr
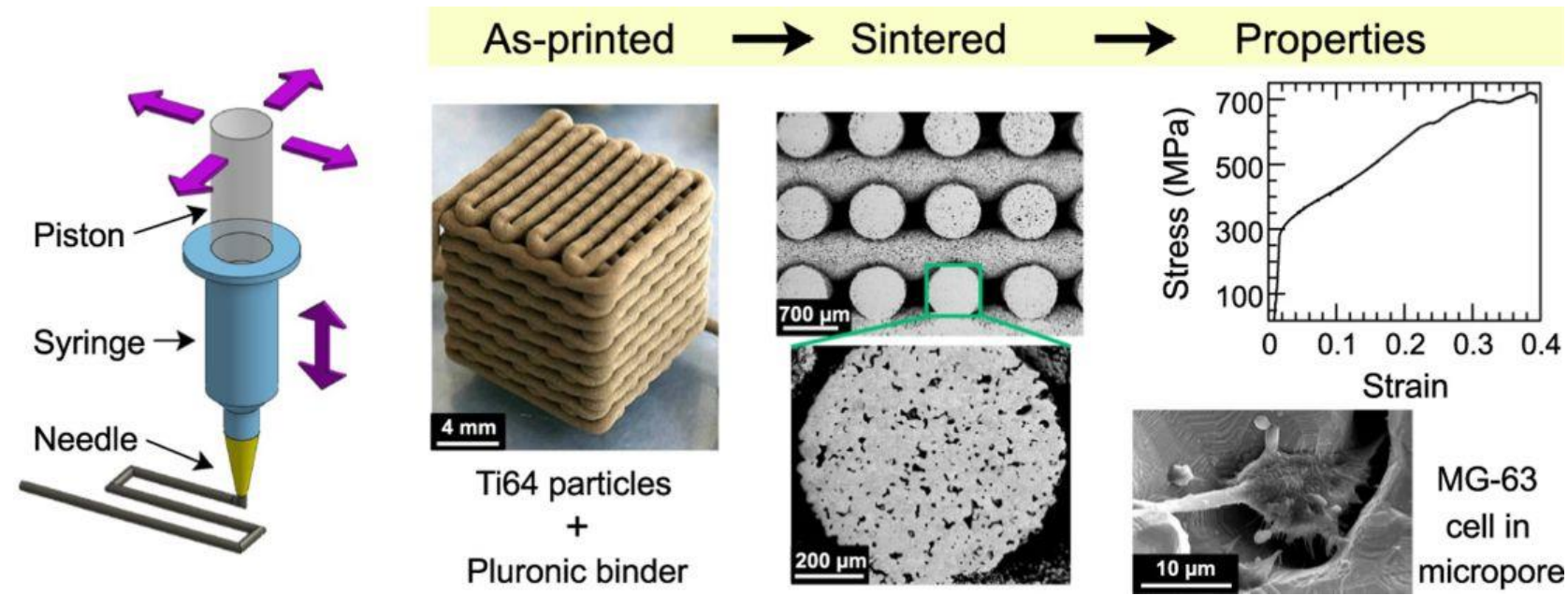

\begin{abstract}
Additive manufacturing of porous Ti6Al4V (Ti64) parts is promising for biomedical applications. In this study, Ti64 scaffolds with two scales of interconnected porosity networks were developed using a direct-ink writing process. Inks were made by dissolving a copolymer (Pluronic F-127) in water to obtain a hydrogel, which was then loaded with Ti64 particles. Both Pluronic F-127 amount in the hydrogel and solid loading influenced ink printability, as shown by rheological measurements and printing accuracy investigation. The best compromise was obtained for a $25 \mathrm{wt} \%$ Pluronic hydrogel loaded with $50 \mathrm{vol} \%$ of Ti64 particles. A partial sintering of $2 \mathrm{~h}$ at $1200{ }^{\circ} \mathrm{C}$ led to interconnected micropores within strut, which was characterised by X-Ray computed tomography. Sintered scaffolds presented a compressive strength higher than bone, with a similar Young's modulus. According to their biocompatibility, final microstructure and mechanical properties, these scaffolds show a promising potential for load-bearing implants.
\end{abstract}

\section{Keywords}

Direct-Ink Writing ; Titanium scaffold ; Sintering ; Microstructure ; Compression 


\section{Introduction}

Rapid population growth and aging induce an increasing demand for bone implants. The high toughness of metals makes them excellent candidates for load-bearing applications [1], and they have been commonly used in orthopaedic surgery for more than one century [2]. Among metallic materials routinely used in orthopaedic implants (stainless steels, cobalt-based alloys and titanium based alloys), titanium alloys present the best strength-to-weight ratio and the most suitable mechanical properties. However, it is still needed to reduce the stiffness of titanium based implants and enhance their biological fixation. Indeed, stiffness mismatch between an implant and surrounding bone tissue leads to stress-shielding phenomenon [3,4], and poor osseointegration that may increase relative micro-motions risks (between the implant and the hosting bone tissue). These two phenomena are known to result in aseptic loosening of the implant, which is the most common cause of arthroplasty failures [3].

To address these issues, different approaches are possible. Many studies aim at enhancing cell adhesion by modifying implant surfaces in terms of roughness, using sand blasting [5,6], machining $[7,8]$ or chemical etching methods $[6,9]$, but also with anodisation $[10,11]$ or ion implantation $[12,13]$. Going further in this direction of improving osseointegration, plenty of works have been realised on coating the titanium surface with a bioactive material, such as hydroxyapatite $[14,15,16]$, bioactive glasses [15,17], calcium silicates [18,19], titanium nitride [20] or collagen [21].

In parallel, one of the trends to reduce titanium implants stiffness is to develop metastable $\beta$ titanium alloys [3,22]. However, another leading trend that targets both stiffness decrease and osseointegration improvement consists in developing porous titanium implants with interconnected pores that promote cell invasion, bone formation and vascularisation.

Various techniques can be used to produce scaffolds for biomedical applications [23]. While conventional powder metallurgy processes, freeze-casting, gel-casting, or polymer padding have been successfully used to develop porous titanium [24-28], they do not enable to fully control pore shape, size and location, and their interconnectivity. In light of this, additive manufacturing AM techniques such as Electron Beam Melting (EBM) and Laser Beam Melting (LBM) are promising processes to produce implants with controlled architectures and patient-specific implants [29-31].

Parts obtained by EBM and LBM can present an interconnected porosity network with a pore size usually above $300 \mu \mathrm{m}[29,30,32,33]$, which is wide enough to allow vascularisation [34]. But while vascularisation through macropores is actually needed for bone formation and long-term stability as it allows cells feeding, numerous studies suggest that micropores (smaller than $100 \mu \mathrm{m}$ ) can also improve bone ingrowth [35,36]. O'Brien et al. showed a linear relationship between specific surface area and cell attachment [37]. This is in agreement with the increased bone volume fraction that has been observed in the presence of micropores [38,39]. Bohner et al. also concluded that mineralised tissue formation requires interconnected micropores with a mean size larger than $1 \mu \mathrm{m}$ [40]. Thus, designing parts with both macro- and micro-porosity networks seems of interest.

This second microsized porosity network (in addition to the macropores) can hardly be obtained by powder bed fusion technologies but might be more easily achieved by Direct-Ink Writing (DIW). Indeed, DIW consists in the deposition layer by layer through a fine nozzle, of a slurry (the ink) containing the powder of interest dispersed in a binder. The obtained structure then undergoes thermal treatments to be debinded and sintered and thus achieves its final properties. Macropores can be designed during the ink deposition while the microporous network might be obtained through a partial sintering. However inks rheological properties need to be well controlled to enable the success of the shaping process. This can be achieved by tuning the binder composition or the solid loading ratio in the ink [41-44]. And while this versatile process was first extensively studied to obtain ceramic parts [41, 45-49], it is now beginning to be transferred to metallic parts processing [50-53]. Jakus et al. showed that DIW is adequate to fabricate green parts of many different metals. However their process involves the printing of metal oxides and their reduction to the metallic state during sintering in reducing atmosphere [51]. This technique is thus not adequate to the processing of titanium scaffold, titanium oxides being extremely difficult to reduce to metallic Ti. 
Thus, DIW of titanium scaffolds has been explored by few authors: Li et al. manufactured titanium porous scaffolds that exhibit interesting cells activity [50,54]. In 2019, Chen et al. produced titanium foams by DIW using a promising biocompatible polymer as binder [55]. Meanwhile, Elsayed et al. $[53,56]$ used DIW to print titanium scaffolds of different strut diameters, with struts as dense as possible. These studies highlight the benefit of using DIW to produce load-bearing implants with relevant biological properties. However, the authors did not explore the role of either ń intra $\dot{z}$ struts pores or a hybrid pore size distribution (micropores in the struts and macropores by design) on the resulting biological or mechanical properties.

In this study, we used DIW because it combines the advantage of being able to produce pores by design (at a scale between 100 and $1000 \mu \mathrm{m}$ ) with the advantage of conventional sintering techniques, where different powder particles sizes and/or thermal treatments can lead to different pores at the micron scale.

We used different water-based Ti6Al4V (Ti64) inks to optimise the shaping step of DIW. We produced Ti64 scaffolds with two levels of interconnected porosities and characterised them after each processing step. Finally, we measured their final mechanical properties and biocompatibility to evaluate their ability to be used as load-bearing bone implants.

\section{Materials and experimental procedure}

Ti-6Al-4V (Ti64) argon atomised powder used in this study has been purchased from TLS Technik GmbH (Germany). Its chemical composition is given in Table 1.

The poly(ethylene oxide)-poly(propylene oxide)-poly(ethylene oxide) triblock co-polymer surfactant was furnished by Sigma Aldrich (referred to as "Pluronic F-127" in the following). It was used in the form of dried granules for the binder preparation.

Table 1: Composition of the Ti64 powder according to the supplier.

\begin{tabular}{l|llllllll}
\hline Chemical element & $N$ & $C$ & $H$ & $F e$ & $O$ & $A l$ & $V$ & $T i$ \\
\hline Composition (wt\%) & 0.005 & 0.01 & $<0.001$ & 0.22 & 0.08 & 6.20 & 3.98 & Bal. \\
\hline
\end{tabular}

\subsection{Fabrication strategy \\ 2.1.1. Ink formulation}

To be printable, an ink should present a shear-thinning behaviour, that enables extrusion through a nozzle under pressure. But as explained by M'Barki et al., it should also present a dynamic yield stress high enough to compensate both gravity (taking into account the weight of the whole printed structure) and capillary forces [57]. This would give the ink the capability to retain its shape just after printing and support the following layers.

To reach those requirements, a well-established practice is to disperse the powder of interest in a solution of Pluronic F127, which exhibits a liquid/gel transition temperature near room temperature [47,58] and adequate rheological properties in its gel state to be printed by DIW [45-49,52,59].

In this study, 20, 25 and $30 \mathrm{wt} \%$ of Pluronic F-127 have been gradually dissolved in distilled water to be used as binder solutions. Before adding the Ti64 powder, those solutions are stored at $4{ }^{\circ} \mathrm{C}$, below the transition temperature, in order to be kept in their liquid state.

To study the printability, each binder has been loaded with 40, 45, 50 and 55 vol\% of Ti64 powder. For each ink, Ti64 addition was carried out in three stages. The batches were mixed in a dual asymmetric centrifugal mixer (SpeedMixer DAC 150.1 FVZ-K) for $1 \mathrm{~min}$ at 1500, 1700 and $2000 \mathrm{rpm}$ after the first, the second and the last addition, respectively. Before each mixing step, inks were kept for $10 \mathrm{~min}$ at $4{ }^{\circ} \mathrm{C}$, in order to be mixed when liquid.

The nomenclature given in Table 2 is used to identify the studied hydrogels and inks.

Table 2 : Inks composition and nomenclature.

\begin{tabular}{|c|c|c|c|}
\hline \multirow[t]{2}{*}{$\begin{array}{l}\text { Ti64 powder } \\
\text { content (vol\%) }\end{array}$} & \multicolumn{3}{|c|}{ Pluronic content in the gel (wt\%) } \\
\hline & 20 & 25 & 30 \\
\hline 0 & P20 & P25 & P30 \\
\hline 40 & P20T40 & P25T40 & Р30T40 \\
\hline 45 & P20T45 & P25T45 & P30T45 \\
\hline 50 & P20T50 & Р25T50 & P30T50 \\
\hline 55 & P20T55 & P25T55 & P30T55 \\
\hline
\end{tabular}




\subsubsection{D printing by DIW}

Printing was completed using a robocaster (3D Inks, LLC, Stillwater, OK, USA) controlled by the motion software Aerotech A3200 (Aerotech Inc., Pittsburgh, PA, USA). Samples were printed on glass plates, covered with a thin layer of grease, to help the removal of dried samples. Inks were extruded at $10 \mathrm{~mm} \mathrm{~s}^{-1}$ through conical nozzles with various internal diameters of 840, 610, 410 and $250 \mu \mathrm{m}$. For all samples, the rod spacing (distance between two rod centres) was fixed at 1.5 times the internal diameter of the nozzle to be comparable to the study conducted by Elsayed et al. [53]. Similarly, the space between two layers along the building direction was fixed at 0.8 times the internal diameter of the nozzle, in order not to crush the filaments too much while ensuring a slight interpenetration [60]. This geometry results in a relative density of $67.86 \%$, considering fully dense struts. To ensure a stabilised flow during scaffold printing, a sacrificial length (few $\mathrm{mm}$ ) of ink was extruded before printing each sample. For all samples, the temperature was maintained at $25{ }^{\circ} \mathrm{C}$ in the printing chamber.

\subsubsection{Debinding and sintering}

Printed scaffolds were dried $48 \mathrm{~h}$ at room temperature (above $22{ }^{\circ} \mathrm{C}$ ) before being removed from the glass substrate. Then, they were thermally debinded and sintered, using a Nabertherm $\mathrm{N} \mathrm{11/hr}$ furnace with an in-house set up enabling a controlled atmosphere. The debinding treatment was chosen according to thermogravimetric analysis:

- a heating rate of $1{ }^{\circ} \mathrm{C} \mathrm{min}^{-1}$ from room temperature to $350{ }^{\circ} \mathrm{C}$.

-30 min at $350{ }^{\circ} \mathrm{C}$.

- a cooling rate of $1{ }^{\circ} \mathrm{C} \mathrm{min}^{-1}$.

The whole debinding treatment was carried out under primary dynamic vacuum (around $5 \times 10^{-2} \mathrm{mbar}$ ).

Finally, samples were sintered $2 \mathrm{~h}$ at $1200{ }^{\circ} \mathrm{C}$, using a heating rate of $10{ }^{\circ} \mathrm{C} \mathrm{min}^{-1}$ and the natural cooling rate of the furnace that decreases from $20^{\circ} \mathrm{C} \mathrm{min}^{-1}$ to less than $1{ }^{\circ} \mathrm{C} \mathrm{min}^{-1}$ as the temperature drops. The sintering step was performed under dynamic secondary vacuum (below $5 \times 10^{-4} \mathrm{mbar}$ ).

\subsection{Characterisation}

\subsubsection{Particle Size Distribution}

Particle size distribution measurements were conducted on the as-received Ti64 powder using the dry dispersion unit "Scirocco 2000" of Laser Diffraction Analyser (Mastersizer 2000, Malvern Instruments Ltd, UK). Three measurements were performed, using 2.611 as refractive index value.

\subsubsection{Rheology}

Rheological studies were carried out on a Kinexus Pro+ rotational rheometer (Malvern Instruments Ltd., England), fitted with a $40 \mathrm{~mm}$ parallel plate geometry. Plates were roughened to minimise the risk of slip and a solvent trap was used to prevent drying. The temperature was maintained at $25^{\circ} \mathrm{C}$ during tests.

Flow curves were obtained using a decreasing shear rate ramp from 200 to $1 \mathrm{~s}^{-1}$. To measure static and dynamic yield stresses, the stress-shear rate loop proposed by M'Barki et al. has been used [57] (see Figure 1 (a)). This loop was chosen to approach the printing conditions, by applying an increasing controlled ramp until ink extrusion, followed by a decreasing shear rate controlled ramp. This second ramp allowed to imitate stress release and relaxation that lead to the dynamic yield stress when printing is completed. Yield stresses were evaluated by fitting the data to the Herschel-Bulkley equation (see equation 1).

Gel and ink structure recovery was measured by following Gioffredi et al. procedure [58]. First, gel and inks were destructured under a $100 \mathrm{~s}^{-1}$ shear rate for $10 \mathrm{~s}$. Then, while they were submitted to a $100 \mathrm{~Pa}$ stress, their viscosities were measured as a function of time. Note that the shear rate chosen to destroy gel and ink structures, corresponds to the maximum shear rate that can be seen by an ink printed at $10 \mathrm{~mm} \mathrm{~s}^{-1}$ through a $250 \mathrm{~mm}$ nozzle diameter, as estimated using a laminar flow model $[57,61]$.

\subsubsection{Thermogravimetric Analysis}

Thermogravimetric analyses were conducted using a TGA Q50 analyser, equipped with an EGA furnace (TA Instruments, New Castle, USA). Mass losses were followed during a heating rate of $1{ }^{\circ} \mathrm{C} \mathrm{min}^{-1}$ from room temperature to $500{ }^{\circ} \mathrm{C}$ under of $150 \mathrm{~mL} \mathrm{~min}{ }^{-1}$ nitrogen flow (after a purging step).

\subsubsection{Scanning electron microscopy}

Images of structures were acquired within a Tescan Vega3 scanning electron microscope (SEM) equipped with a tungsten filament (Tescan Orsay Holding, a.s., Brno, Czech Republic). Both secondary electrons (SE) and backscattered electrons (BSE) modes have been used.

Electron Backscatter Diffraction (EBSD) map acquisitions were performed in a SEM Zeiss Supra 55 VP with fieldemission gun, equipped with an Oxford Instrument EBSD Symmetry camera. EBSD maps were performed using an acceleration voltage of $20 \mathrm{kV}$, with an aperture size of $120 \mu \mathrm{m}$, in the high current mode. The step size was fixed at 200 $\mathrm{nm}$, in order to well detect the $\beta$ phase.

EBSD maps were post-treated using Channel 5 software and a $5^{\circ}$ grain boundary criterion to calculate the mean grain size. 
a)

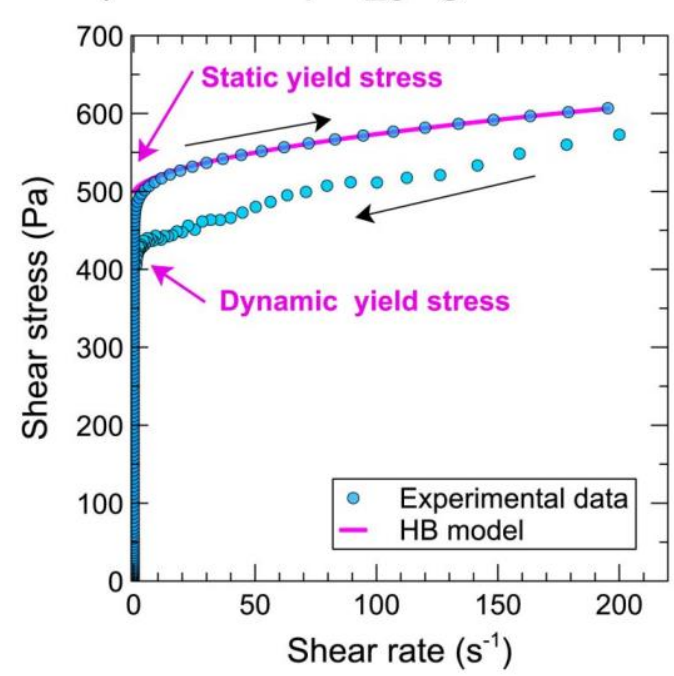

c)

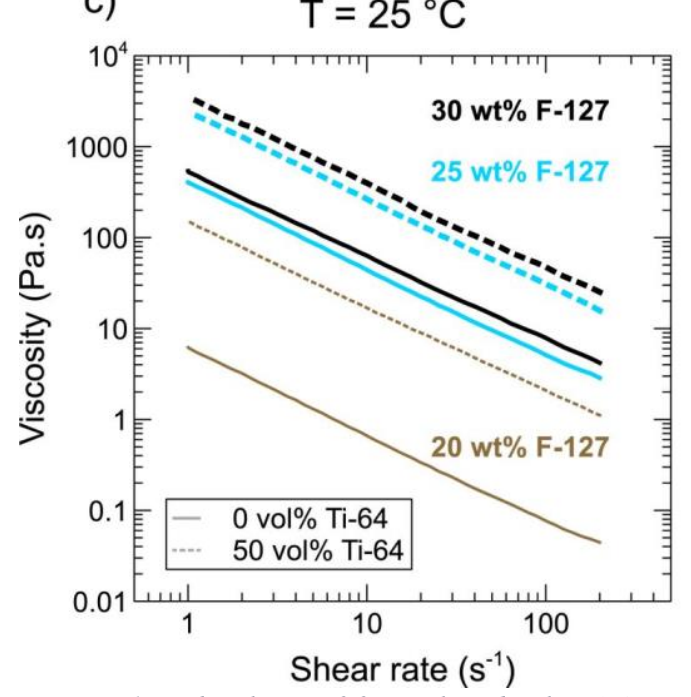

b)

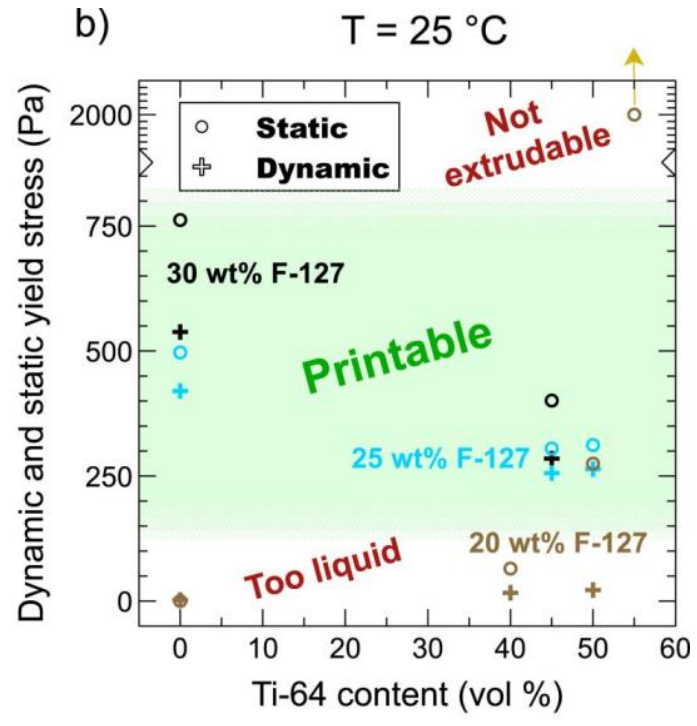

d)

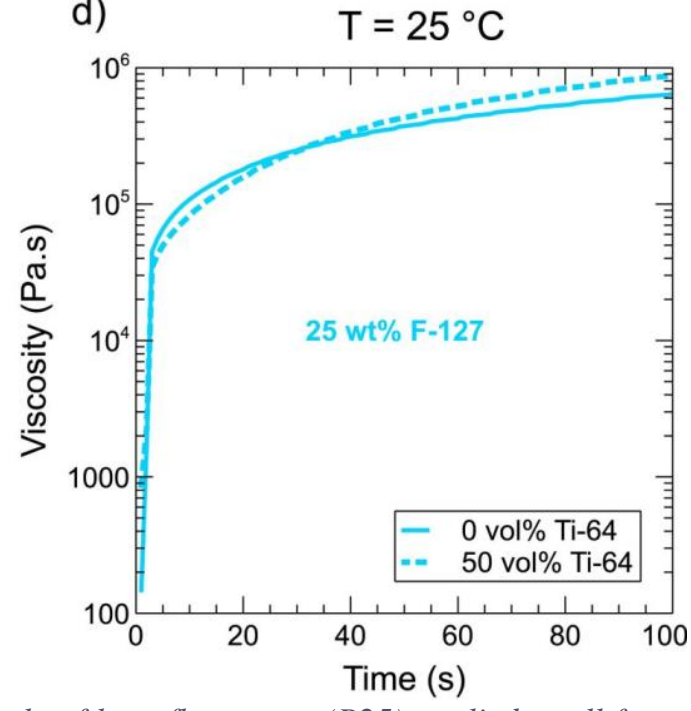

Figure 1: Rheology of formulated inks: (a) example of loop flow curve (P25) applied to all formulated inks; (b) static and dynamic yield stresses of binders and inks; (c) viscosity versus shear rate of the 3 binders and the 3 inks at 50 vol.\%Ti64; (d) Recovery time of P25 and P25T50 (cf Table 2 for the nomenclature).

\subsubsection{X-Ray diffraction}

X-Ray diffraction (XRD) patterns were acquired using a Bruker AXS D8 Advance Diffractometer with a Cu tube (30 $\mathrm{mA}, 40 \mathrm{kV}$ ) and a $0.6 \mathrm{~mm}$ diffusion slit. Diffracted X-Rays were collected with a Lynxeye detector, between 20 and $60^{\circ} 2 \theta$ (since this range includes all main Ti diffraction peaks), with steps of $0.02^{\circ}$ at $1 \mathrm{~s} / \mathrm{step}$. XRD patterns were then analysed using Eva software (Brucker) and Rietveld refinement was performed on Topas software for phase fraction quantification.

\subsubsection{X-Ray tomography}

Parts printed with a needle of $840 \mu \mathrm{m}$ diameter were analysed by X-Ray computed tomography. Dried or sintered whole scaffolds were scanned using a V|tome|x device (GE Sensing \& Inspection Technologies Phoenix X-Ray GmbH, Boston, MA, USA) $\left(0.1 \mathrm{~mm} \mathrm{Cu}\right.$ filter, $100 \mathrm{kV} \mathrm{X}$-Ray tube voltage, 1200 projections over $360^{\circ}$ rotation, 3 images per projection, $667 \mathrm{~ms}$ exposure time, $8 \mu \mathrm{m}$ voxel size). Sintered mono-filaments printed with a nozzle of $840 \mu \mathrm{m}$ were imaged at high resolution using an EasyTom Nano tomograph (RX Solutions, Chavanod, France) (100 kV X-Ray tube voltage, 1248 projections over a $360^{\circ}$ rotation, 3 images per projection, $4 \mathrm{~s}$ exposure time, $0.45 \mu \mathrm{m}$ voxel size). In both cases $3 \mathrm{D}$ volumes were reconstructed from the collected radiographs using a filtered back projection Feldkamp-algorithm. Images analysis was then performed using the free and open-source Fiji software [62].

To quantify the robocaster precision associated which each ink, scans of dried scaffolds were compared to the CAD design files. First, the two structures were aligned by authorising the rigid-body translation/rotation. Then, signed Euclidean distance transform operator was applied to the CAD design to get, at any point in space, the closest Euclidean distance to the surface of the CAD design. This distance was considered as positive for voxel outside of the CAD struts and negative for voxel included in CAD struts. Finally, the value of this distance field was extracted for any point on the actual surface, giving the signed Euclidean distance from the ideal surface closest to the observed actual surface point. 


\subsubsection{Shrinkage}

Measurements were performed on X-Ray tomography scans of sintered scaffolds and filaments, and compared with CAD dimensions to obtain the process shrinkage. To be sure to work on structures completely perpendicular with the observation axis, sintered structures were first aligned with CAD design files as explained previously. This alignment is important to measure the right dimensions as an angle would introduce a bias (sine or cosine). Once the structure is well oriented, Fiji software enables to sum all the projections in the stack. This gives the enveloping outer shell of the structure in the plan of observation, whose dimensions can be accurately measured at pixel level $(0.45 \mu \mathrm{m})$. This is repeated for the three plans of observation: $(\mathrm{x}, \mathrm{y}) ;(\mathrm{x}, \mathrm{z})$ and $(\mathrm{y}, \mathrm{z})$.

\subsubsection{Density}

The eight scaffolds used to determine shrinkage were also weighed. Each mass obtained was divided by the corresponding scaffold volume to get their density. These volumes were calculated from the dimensions derived from X-Ray tomography scans as previously explained. The Ti64 density used to obtain scaffolds relative density was $4.43 \mathrm{~g} \mathrm{~cm}^{-3}$.

\subsubsection{Porosity}

Internal porosity (within filaments) was quantified by X-Ray tomography scans analysis performed with Fiji software. After binarisation, a mask is obtained from each scan of filaments by filling all pores. The initial binarised scan is then subtracted from this mask to only keep pores. Then pores are labelled (one label per pore) to get dimensional information on each of them, authorising to plot a pore size distribution. Labels containing eight voxels or less are considered as noise and are not kept for characterisations. The volume fraction of porosity is obtained by comparing the number of voxels included in the mask with the number of voxels included in the labelled pores. In addition, Fiji is able to detect edges. Thus by adding the edges of the mask to the stack of pores, it is possible to determine which ones are open (in contact with the edge of the mask), and which ones are closed.

\subsubsection{Mechanical tests}

Vickers hardness tests were performed under $500 \mathrm{gf}$ loads, on a previously polished cross-section, perpendicular to the building direction. The average value was calculated on more than 10 measurements.

Compressive tests were conducted using an Instron 8502, equipped with a $100 \mathrm{kN}$ load cell. Tests consisted in a preload of $100 \mathrm{~N}$, followed by a strain rate of $0.05 \mathrm{~min}^{-1}$. One side of the tested sample was filmed using a mvBlueFox camera, to follow sample surface damages. Three roughly cubic samples printed with the $840 \mu \mathrm{m}$ nozzle diameter were tested. They were made of eighteen layers of ten struts ( $\sim 10.2-10.3 \mathrm{~mm}$ side after sintering), to follow Ashby's advice on preventing size effect by having at least seven times the foam cell size in each direction [63]. Upper and lower surfaces were polished prior to tests, in order to get flat and parallel surfaces. Stress-strain curves were then obtained after correcting the data from the machine stiffness (measured on a sample with known stiffness: aluminium alloy 2017A at T4 with a Young's modulus of $74 \mathrm{GPa}$ ). One compressive test was interrupted several times at different loads, to enable the evaluation of damage in 3D by X-Ray tomography.

\subsubsection{Cell proliferation}

Scaffolds were printed with a $610 \mu \mathrm{m}$ needle size and the number of printed struts by layer were reduced to obtain parts fitting in $1 \mathrm{~cm}$ diameter wells. To prevent all the cells from falling directly to the bottom of the well at the time of deposition, robocasted samples were designed using the following characteristics:

- A first dense layer (without macropores)

- A contour present over the entire height of the part

- Two additional layers composed of 7 filaments separated by $310 \mu \mathrm{m}$ (920 $\mu \mathrm{m}$ between two filament centres) with the second layer oriented at $90^{\circ}$ to the first.

The overlap between layers was kept as 0.8 times the needle diameter.

Samples were sterilised by dry heat with a 30 min treatment at $180{ }^{\circ} \mathrm{C}$. Tests were carried out in 24 -well plates specifically treated for cell culture. Empty wells have therefore been used as controls (plastic reference P-Ref) in addition to polished Ti64 discs control (Ti64-Ref).

A suspension of 5000 MG-63 cells was deposited on each sample. A period of 2 hours was left to allow cell adhesion before adding the culture medium. Cells proliferation was measured after 24 hours of culture in contact with the materials to assess cytotoxicity and after 3, 7 and 10 days of culture to assess cell proliferation. Incubations were carried out at 37 ${ }^{\circ} \mathrm{C}$ under humid atmosphere with $5 \% \mathrm{CO}_{2}$. Evaluations of cell proliferation were carried out using the PrestoBlue technique: the blue, non-fluorescent resazurin is reduced by the metabolic activity of the cells in fluorescent resafurin. The desired day, $1 \mathrm{~mL}$ of medium containing $10 \mathrm{vol} \%$ PrestoBlue was added to each well. After $1 \mathrm{~h} 30$ of incubation, $100 \mu \mathrm{L}$ of medium was taken from each well and transferred to a black-bottomed plate. Results were read using the INFINITE PRO 200 fluorimeter (excitation $535 \mathrm{~nm}$, emission $610 \mathrm{~nm}$, gain 40).

This study was carried out in triplicate and repeated three times (independently of each other).

To confirm these results and better visualise what is occurring, one sample from each case was observed by SEM for each incubation time. The cells were then fixed on the samples using a $2 \%$ Glutaraldehyde solution in which they were left for 1 hour before being rinsed with a buffer solution. 


\section{Results and discussion}

The aim of this study was to understand and optimise all the steps of the robocasting process. Thus characterisations were performed at each step including the initial state.

\subsection{Ti64 initial powder}

The as-received powder was characterised in terms of particle size distribution, morphology and microstructure (Figure 2).
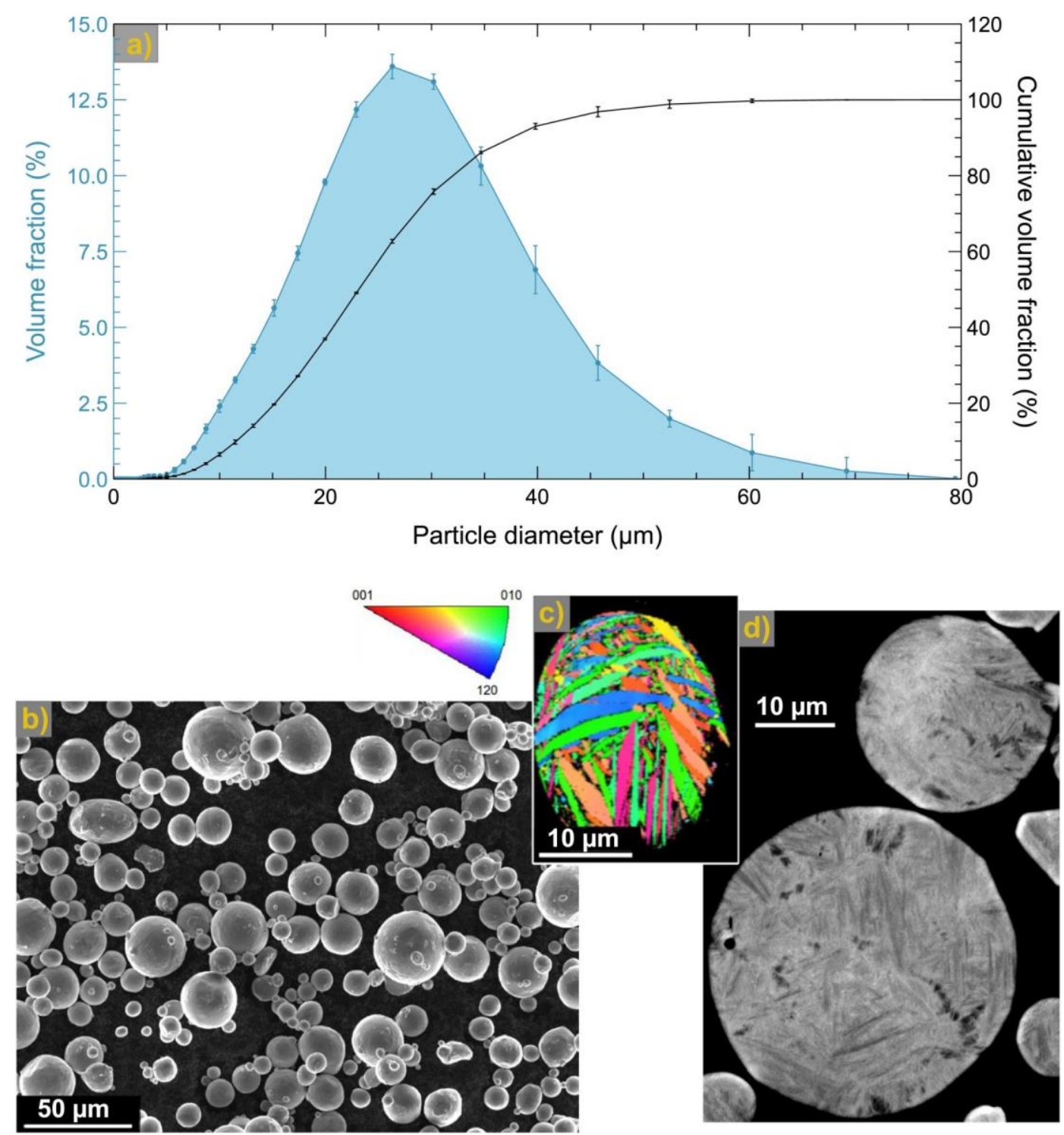

Figure 2: As-received powder: (a) Particle size distribution; (b) SE image of the Ti64 powder; (c) EBSD Inversed Pole Figure (IPF) map of a powder particle; (d) BSE image on particles cross-section showing lamellar structure.

According to the laser diffraction results, Ti64 particles diameters range between 2 and $70 \mu \mathrm{m}$ (Figure 2 (a)). The distribution is characterised as follows: $D_{10}=(11.6 \pm 0.2) \mu \mathrm{m} ; D_{50}=(23.1 \pm 0.1) \mu \mathrm{m}$ and $D_{90}=(37.2 \pm 0.4) \mu \mathrm{m}$.

Powder particles are round-shaped due to gas atomisation (Figure 2 (b)). Ti64 is in its hexagonal structure ( $\alpha$ phase) and presents a lamellar microstructure with micron-thick laths (Figure 2 (c) and $(d))$, which is characteristic of a fast cooling rate. 


\subsection{Ink formulation and characterisation}

Different inks have been formulated (as detailed in the material and experimental procedure section) to establish a printability domain in terms of ink composition. To do so, both rheological measurements and shape investigations on as-printed scaffolds were performed and correlated.

\subsubsection{Printability}

All studied inks have been printed. In parallel, rheological measurements were performed to obtain both static and dynamic yield stresses and define a printability domain. Figure 1(a) shows flow curves loop used to determine static and dynamic yield stresses. Obtained values are reported on Figure 1 (b). As already described in the literature [49,59], Pluronic-F127 hydrogel (loaded with particles or not), can be described by the Herschel-Bulkley model that can account for both the presence of a yield stress and a shear-thinning behaviour (equation 1) [64]:

$\sigma=\sigma_{y}^{0}+K \dot{\gamma}^{n}$

where $n$ is the pseudoplasticity index $\left(0<n<1\right.$ in shear-thinning fluids), $\sigma_{y}^{0}$ is the yield stress $\left(\sigma_{y}^{0}>\right.$ 0 ) and $K$ is the consistency index.

Except the $20 \mathrm{wt} \% \mathrm{~F}-127$ (which does not exhibit a yield stress probably due to incomplete gelation at $25{ }^{\circ} \mathrm{C}$ ), all studied gels and inks follow an Herschel-Bulkley model with $0.3<n<0.7$, meaning that they are shear-thinning. This behaviour is also highlighted by their decrease in viscosity when increasing shear rate, as shown on Figure 1 (c). This decrease in viscosity can be explained by the gel destruction under shear.

Increasing the amount of pluronic F-127 in the hydrogel, or the solid loading in the ink does not lead to an increase of the shear-thinning behaviour as the slope remains the same. However it leads to an increase of viscosity as already observed in other studies [47,49,52]. This means that the soft network formed by the Pluronic F-127 hydrogel is not affected by the presence of the Ti64 powder but only by the shear stress. The hydrogel might then be able to transport the powder through a nozzle.

It is widely admitted that an ink should present a shear-thinning behaviour to be printable. However, M'Barki et al. also emphasised the important role played by both static and dynamic yield stresses in printability [57]. The static yield stress is the stress to apply on the ink to make it flow from a static state. The dynamic one is the minimal stress needed to maintain the flow when the ink is already moving. Thus, the stress endured by the ink just after printing has to be below this dynamic value to prevent deformation. So the static yield stress gives us information on the ink extrudability, whereas the dynamic one informs us on the ink capacity to retain its shape and support the following layer. Figure 1 (b) shows that all inks made with the $20 \mathrm{wt} \%$ pluronic gel present dynamic yield stresses lower than $50 \mathrm{~Pa}$, and a poor printability (scaffolds collapsed few seconds after printing). Feilden et al. [59] also considered this value of $50 \mathrm{~Pa}$ as a threshold under which DIW is not possible. Those low dynamic yield stresses might be due to incomplete gelation at $25{ }^{\circ} \mathrm{C}$. Gioffredi et al. indeed suggested a lower critical gelation temperature of $28^{\circ} \mathrm{C}$ for this $20 \mathrm{wt} \%$ pluronic gel [58]. These inks might therefore be printable at temperatures higher than $28^{\circ} \mathrm{C}$.

Note that inks containing $55 \mathrm{vol} \%$ metallic particles were not printable (extrusion was not possible with our robocaster). This value of $55 \mathrm{vol} \%$ corresponds to the percolation threshold of hard spheres in a fluid [65], for which stress is transmitted only via metallic particles.

Inks made with the 25 and $30 \mathrm{wt} \%$ pluronic gel lead to acceptable printed scaffolds for the three larger nozzle size (see Figure 3, (h)-(m)). Their associated dynamic yield stresses are larger than $200 \mathrm{~Pa}$. The lower limit of the printable domain lies between 50 and $200 \mathrm{~Pa}$, as represented on Figure 1 (b). Moreover, the presence of particles tends to slightly decrease both yield stresses. This might be due to the presence of discontinuities in the gel caused by the Ti64 particles that seem to have poor interactions with the hydrogel. 

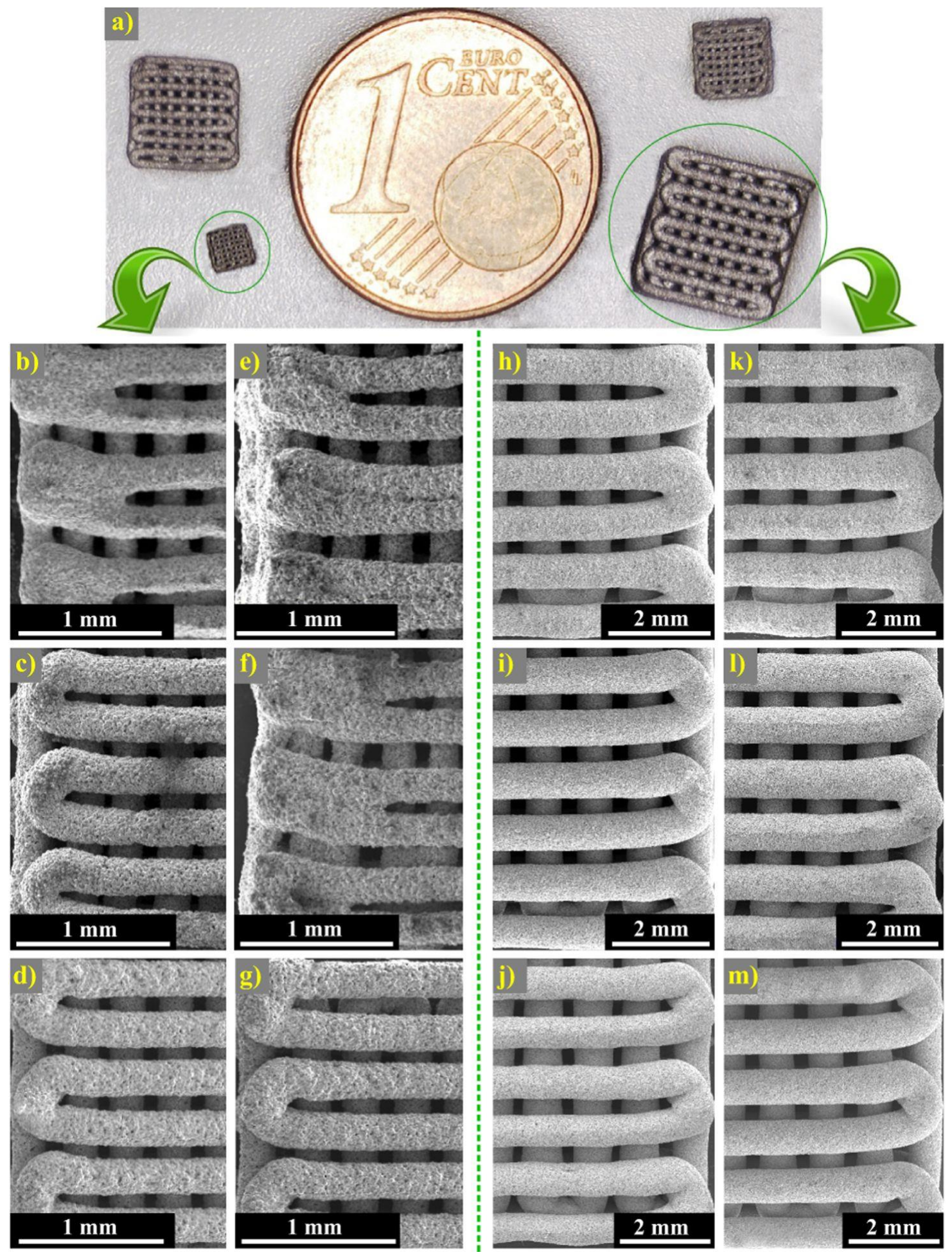

Figure 3 : Morphology after printing: (a) Picture showing the four scaffold sizes, printed with respectively 840, 610, 410 and 250 um nozzle diameter; (b)-(d) Dried scaffolds printed using P25T40 (b), P25T45 (c) and P25T50 (d) inks and the 250 um nozzle; (e)-(g) Dried scaffolds printed using P30T40 (e), P30T45 (f) and P30T50 ( $\mathrm{g}$ ) inks and the 250 um nozzle; ( $h$ )-( $j$ ) Dried scaffolds printed using P25T40 (h), P25T45 ( $i)$ and P25T50 (j) inks and the $840 \mu \mathrm{m}$ nozzle; $(k)-(m)$ Dried scaffolds printed using P30T40 ( $k$ ), P30T45 (l) and P30T50 ( $\mathrm{m})$ inks and the 840 um nozzle.

Another important point for printability is the recovery time of the ink: after being sheared in the nozzle, the ink has to recover a relatively high viscosity in a limited amount of time to preserve the scaffold structure. Figure 1 (d) shows the time evolution of the viscosity of P25 and P25T50, after applying a step shear rate. It can be observed that the presence of metallic particles does not affect the gel recovery time, as also suggested by the proper structure of just printed scaffolds (see Figure 3, (h)-(m)). 
However, down sizing the nozzle diameter leads to less homogeneous extrusion as shown on Figure 3, (b)-(g). This might be due to arch formations within the nozzle (non-constant flows were observed), as the nozzle diameter become too near to the $D_{90}$ of the used powder (ratio $<7$ with the nozzle of $250 \mu \mathrm{m})$. Indeed arches formation that leads to clogging has been observed in both silos [66,67] and narrow vertical pipes without constrictions [68] and is known to depend on both outlet diameter and particle size [66-68].

In regards of rheological properties and structures of dried scaffolds, the three inks made with the 25 $\mathrm{wt} \%$ pluronic hydrogel and the three made with the $30 \mathrm{wt} \%$ pluronic hydrogel seems printable. However for P25T40, P30T40 and P30T45, the nozzle diameter cannot be lowered to $250 \mu \mathrm{m}$ without affecting printability. Thus, only P25T45, P25T50 and P30T50 inks were kept for deeper investigation of printability using 3D characterisation. Also, as samples printed with the $840 \mu \mathrm{m}$ diameter nozzle were easier to handle, the further characterisations were done on this sample size.

\subsubsection{Discrepancy from CAD file}

An example of a distance map obtained by comparing the volume obtained from X-Ray tomography with the CAD file is given on Figure 4 (a). This technique also enables to quantify the dispersion of this discrepancy, normalised here by the total surface area (Figure 4 (b)).
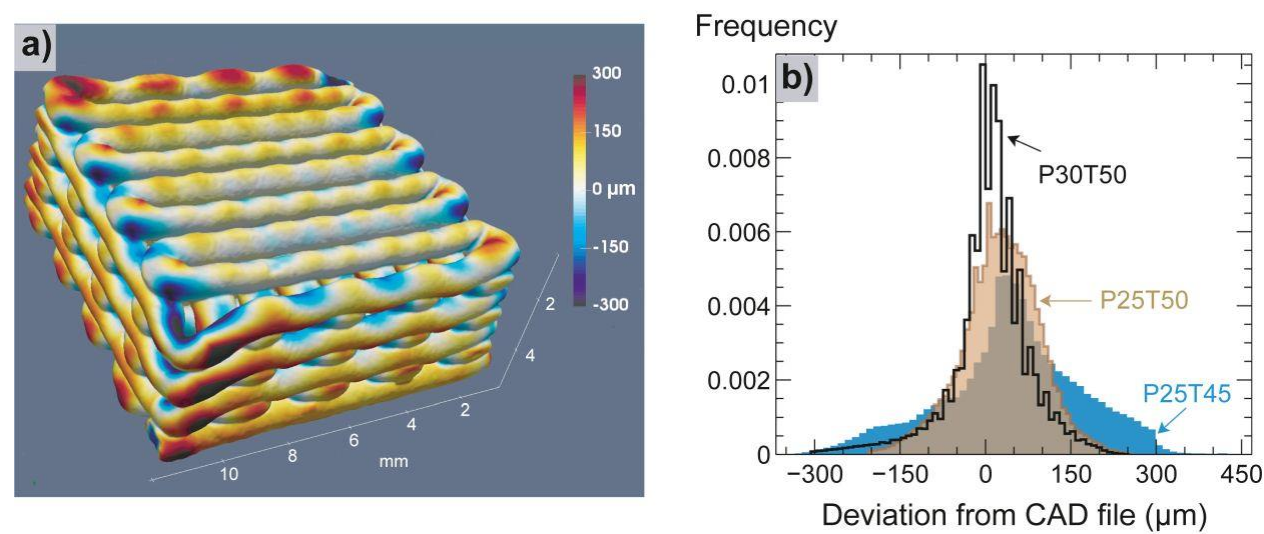

Figure 4: Discrepancy from CAD file: (a) Calculated distance map of a reconstructed scaffold printed with the P25T50 ink; (b) Measured discrepancy for the same scaffold and a scaffold printed with the P25T45 ink.

Table 3 : Deviation from CAD file depending on the ink used.

\begin{tabular}{l|lll} 
Ink & P25T45 & P25T50 & P30T50 \\
\hline Mean discrepancy from CAD $(\mu \mathrm{m})$ & 50 & 30 & 10 \\
Standard deviation of discrepancy from CAD $(\mu \mathrm{m})$ & 130 & 80 & 80
\end{tabular}

Figure 4 (a) shows that the largest deviations from CAD file are located around corners, and when moving from one layer to the next one. This leads to an important standard deviation on the measured value, as presented in Table 3. Note that CAD files used in this study were asking for two closely spaced right angles, where a circle arc would have been easier to draw. Also, we used in this study the same printing speed for all printed segments. However, it might be relevant for the future to verify if slowing down when cornering enhances the precision.

Standard deviations given in Table 3 reflect the distribution width of the discrepancy from CAD file for each ink (see Figure 4 (b)). Thus these values provide a good overview of printing precision, and the ideal case would be to have the narrowest possible distribution.

It should be noted that, if the increase from 45 to 50 vol\% of Ti64 particles in the $25 \mathrm{wt} \%$ pluronic gel leads to a refinement of the distribution, this is not the case for an increase from 25 to $30 \mathrm{wt} \%$ of pluronic in the gel, keeping the solid loading at $50 \mathrm{vol} \%$. It seems that the distribution of the deviation from CAD file cannot be more refined without playing on printing parameters or design.

Thus both P25T50 and P30T50 lead to the best printing accuracy obtained in this study. But to minimise the pluronic content in order to facilitate the debinding step, only the P25T50 ink was kept for further characterisations. 


\subsection{Scaffold structure evolution during process}

\subsubsection{Thermal treatments}

Once printed, scaffolds need to be debinded and sintered to reach their final structure and properties. The debinding parameters were chosen according to the thermogravimetric analysis (TGA) presented on Figure 5. This analysis was performed on both P25 and P25T50.

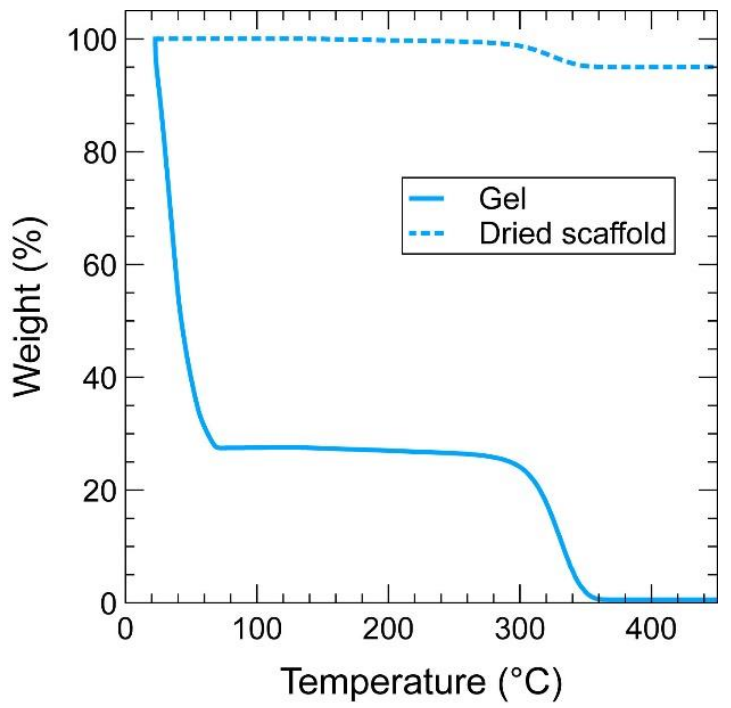

Figure 5 : Thermogravimetric analysis of the P25 hydrogel and a dried scaffold printed with the P25T50 ink.

TGA of the hydrogel (P25) shows two successive mass losses. The first, below $80{ }^{\circ} \mathrm{C}$ corresponds to vaporisation of water. Then degradation of the pluronic F-127 occurs between 300 and $350{ }^{\circ} \mathrm{C}$.

This copolymer degradation is not affected by the presence of Ti64 particles as it occurs within the same temperature range for the dried scaffold. It can be noted that the vaporisation of water is not present here as the ink is already dried. Besides, considering the density of the P25 hydrogel $\left(\rho_{g e l}=\right.$ $\left.1100 \mathrm{~kg} \cdot \mathrm{m}^{-3}\right)$, the density of Ti64 $\left(\rho_{T i 64}=4430 \mathrm{~kg} \mathrm{~m}^{-3}\right)$, and the presence of $50 \mathrm{vol} \%$ of each in the considered ink, the P25T50 ink contains: $1100 /(1100+4430)=19.9 \mathrm{wt} \%$ of hydrogel. In addition the hydrogel contains $25 \mathrm{wt} \%$ of pluronic F-127, meaning that the ink contains $19.9 \times 25 / 100=4.98 \mathrm{wt} \%$ of pluronic F-127. Thus the mass loss found by the thermogravimetric analysis on the dried scaffold is well in agreement with the pluronic content of the ink. Consequently, the debinding step was performed in the same conditions as the TGA: $1{ }^{\circ} \mathrm{C} \mathrm{min}-1$ up to $350{ }^{\circ} \mathrm{C}$, adding a 30 min plateau at $350{ }^{\circ} \mathrm{C}$.

With conventional sintering, temperatures around $1350-1450{ }^{\circ} \mathrm{C}$ are necessary to fully densify Ti64 $[53,69]$. In this study a sintering temperature of $1200{ }^{\circ} \mathrm{C}$ was used as the purpose is to keep a microporous network thanks to partial sintering. Indeed, Chávez et al. showed that using a sintering temperature of $1200{ }^{\circ} \mathrm{C}$ led to around $11 \%$ of porosity in Ti64 samples with particle shape and size similar to the ones used here [70].

Figure 6 shows the scaffold aspect at each processing step (dried, debinded, sintered). BSE image of Figure 6 (b) highlights the presence of the binder and its comparison with the image of Figure 6 (d) emphasises the success of the debinding step. It should be specified that the pluronic does not act as a space holder. It leaves spaces far smaller than pores induced by packing of the rather large titanium particles used here, as shown on Figure 6 (b) and (d). Thus neither debinding parameters nor pluronic content can enable to control intra-strut porosity. Also Figure 6 (c) shows that scaffold structures are preserved during the debinding step. 

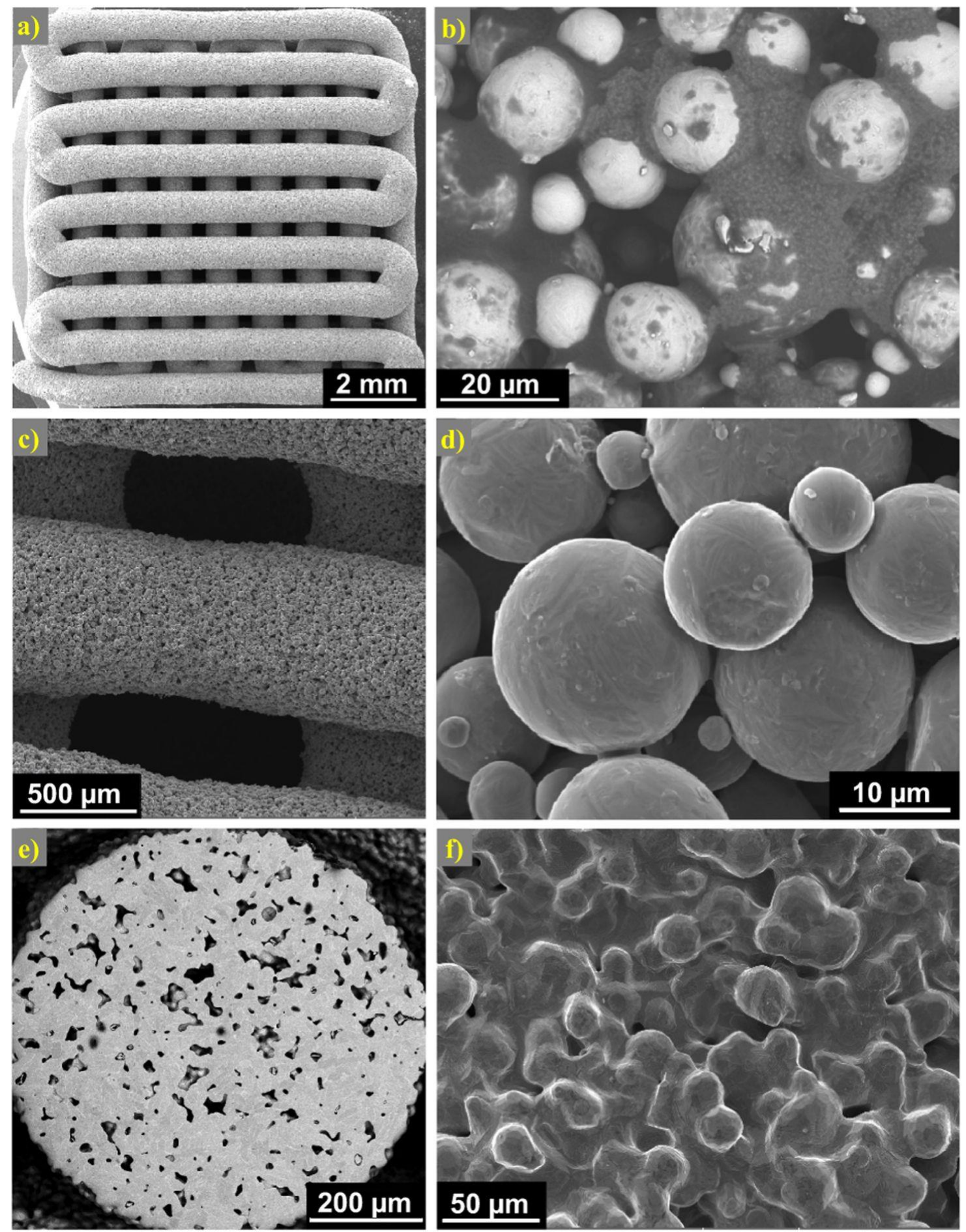

Figure 6: Structure evolution during thermal treatments of scaffolds printed with the P25T50 ink: (a) Dried scaffold; (b) Focus on few particles surrounded by Pluronic F-127 in a dried scaffold; (c) Rods of a debinded scaffold; (d) Focus on few particles of a debinded sample; (e) Cross-section of a sintered scaffold (one rod); (f) Surface aspect of a sintered scaffold.

The focus on one constitutive filament of a sintered scaffold cross-section, presented on Figure 6 (e), shows the remaining intra-strut porosity. As previously explained, this remaining porosity was desired and expected [70], and has been quantified using high-resolution X-Ray tomography (Figure 7). Such a partial sintering leads to the surface aspect shown on Figure 6 (f). 
a)

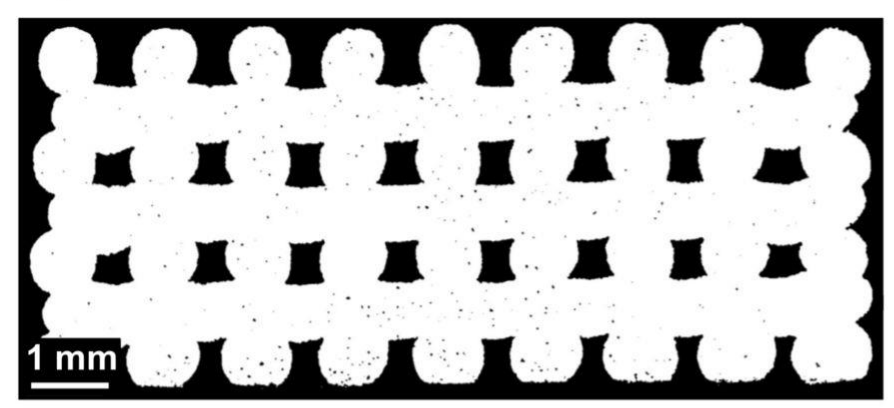

b)

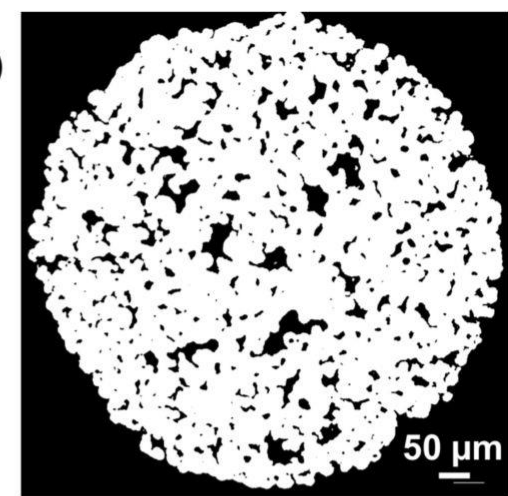

c)

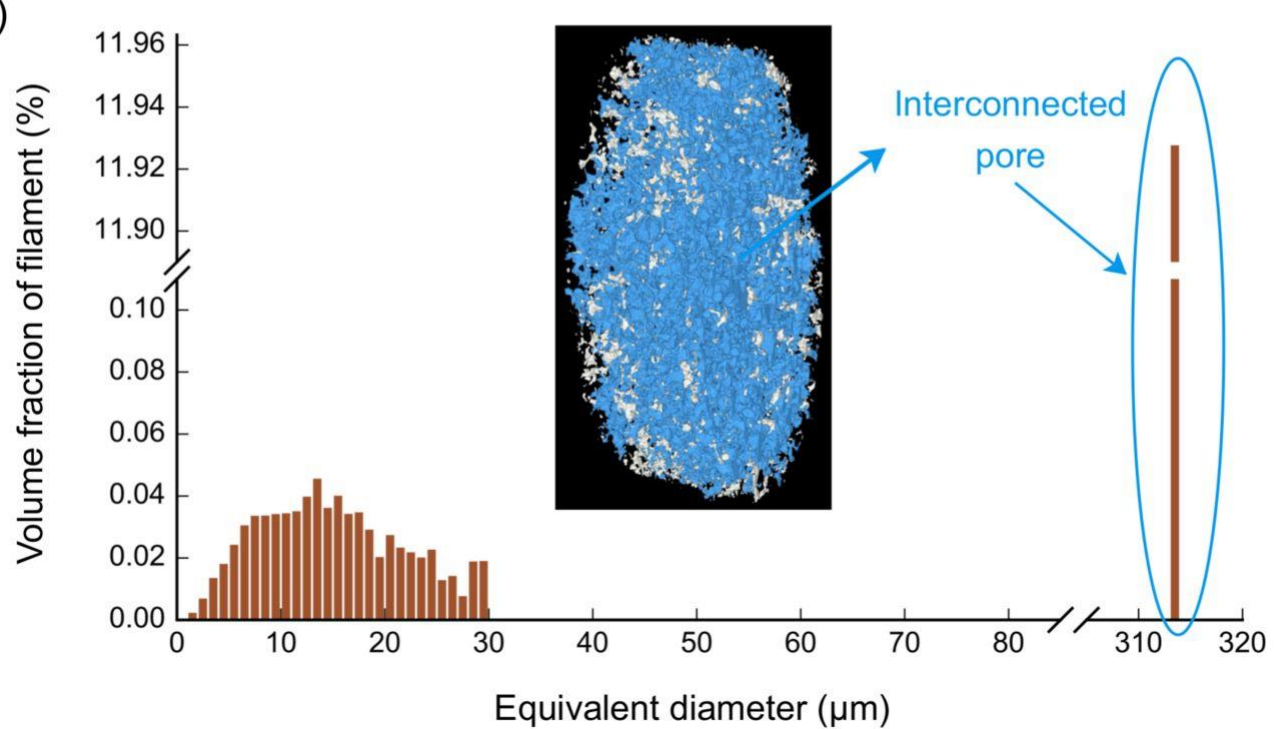

Figure 7 : Final structure with the P25T50 ink: Example of tomographic section of: (a) the whole structure, (b) a constitutive strut; (c) Pore size distribution represented as volume fraction of the filament and its associated $3 D$ porous network reconstruction.

\subsubsection{Architecture and porosity}

An important concern associated with sintering is to control the shrinkage in order to predict the final dimensions of the sintered part from the initial CAD file. Thus, as-sintered dimensions were measured thanks to X-Ray tomography (Figure 7 (a) and (b)). The size of the enveloping outer shell was measured in all three directions for both scaffolds and filaments. These values were compared to the CAD dimensions to get the process shrinkage. Note that as-sintered dimensions obtained by X-Ray tomography were in agreement with measurements realised on SEM images, and shrinkage obtained for filaments was as well in agreement with shrinkage obtained on scaffolds. Results are summarised in Table 4. Same samples have also been weighed to be able to calculate their relative density (compared to Ti64).

Table 4: Process shrinkage and relative density obtained for scaffolds printed with the P25T50 ink and sintered $2 \mathrm{~h}$ at $1200{ }^{\circ} \mathrm{C}$.

\begin{tabular}{l|lll|ll}
\hline \multicolumn{2}{l|}{ Shrinkage (\%) } & & & \multicolumn{2}{l}{ Relative density (\%) } \\
\hline Along $X$ & Along $Y$ & Along $Z$ & Volume & Measured & Designed \\
$15.3 \pm 0.3$ & $15.3 \pm 0.4$ & $15.2 \pm 0.3$ & $39.2 \pm 0.3$ & $57.3 \pm 1.0$ & 59.38 \\
\hline
\end{tabular}

${ }^{*}$ Calculated considering $12.5 \%$ of porosity within struts.

It can be observed that shrinkage is homogeneous in the 3 spatial directions. Also, after sintering macropores size is about $350 \mu \mathrm{m}$ which is appropriate to allow vascularisation [34].

X-Ray tomography high-resolution scans ((Figure 7 (b)) were also used to determine constituent filament density. Figure 7 (c) shows the 3D reconstruction of filament porosity, with the bigger label (corresponding to the bigger pore) coloured in blue, and the associated pore size distribution. This 
highlights the presence of an interconnected porosity present all along the strut. Internal porosity within strut was thus evaluated at $\sim 12.5 \%$ (in strut volume only, see Figure 7 (c)), with an average size of $\sim 15-20 \mu \mathrm{m}$. This internal porosity is composed of $\sim 2.8 \%$ of small closed pores, and $\sim 97.2 \%$ of open porosity. This second porosity network seems then in accordance with the requirement mentioned by Bohner et al. for the formation of mineralised tissues [40].

Thus, scaffolds with two interconnected porosity networks were successfully obtained through DIW and partial sintering at $1200{ }^{\circ} \mathrm{C}$. The $42.7 \%$ of total porosity obtained is made up of $34.5 \%$ of macropores plus $8.2 \%$ of micropores.

\subsubsection{Crystallographic structure}

In order to verify the presence of oxide and carbide phases, easily formed in titanium [71], samples were controlled by XRD after each heat treatment and compared to the initial state (Figure 8).

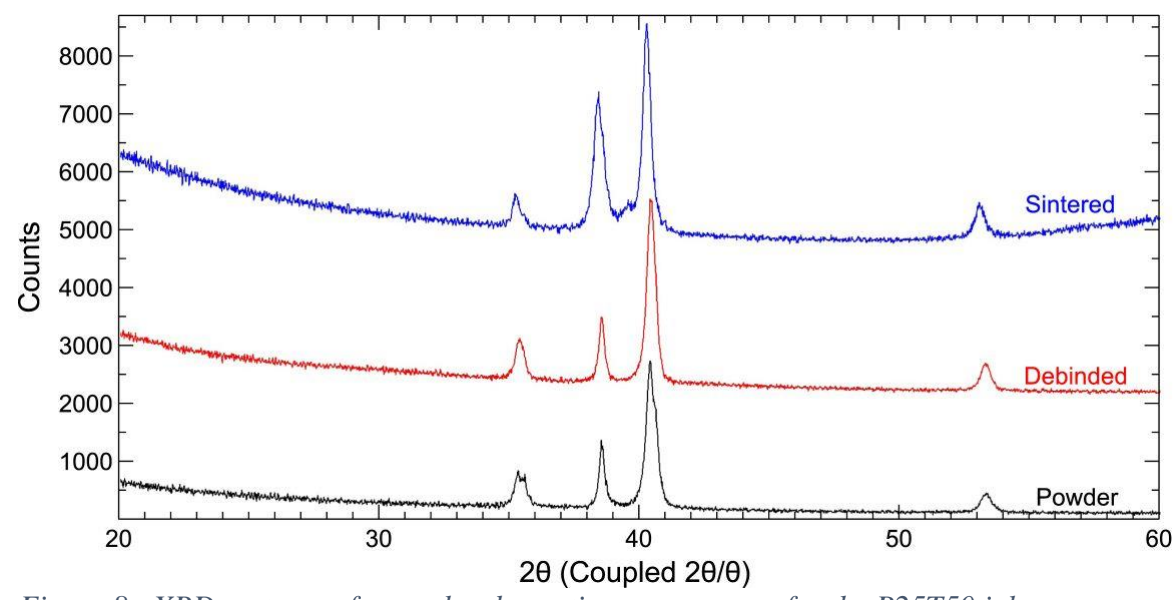

Figure 8:XRD patterns after each robocasting process step for the P25T50 ink.

XRD patterns of initial powder and debinded samples show only the presence of the titanium $\alpha$ phase (Powder Diffraction File (PDF) 00-044 1294), indicating in particular that there was no crystallographic transformation during the debinding step.

The same main titanium phase is detected in the pattern of sintered samples. In addition, a lowintensity peak can be seen between 39 and $40^{\circ} 2 \theta$. This peak can be attributed to the 110 planes of the $\beta$ phase, as calculated using the lattice parameter given by Malinov et al. [72]. A Rietveld refinement performed on this as-sintered pattern gives between 4 and $5 \%$ of $\beta$ phase. Contrary to the previous study conducted by Elsayed et al. on DIW of Ti64 [53], none of the characteristic peaks of TiC are present here, in particular around 36 and $42^{\circ}(2 \theta)$ (PDF 01-1222). The authors think that the low temperature debinding process helps prevent carbon and oxygen diffusion in titanium and further carbide/oxide formation after sintering. A quantitative study of the influence of debinding/sintering schedules on the formation of brittle phases is ongoing.
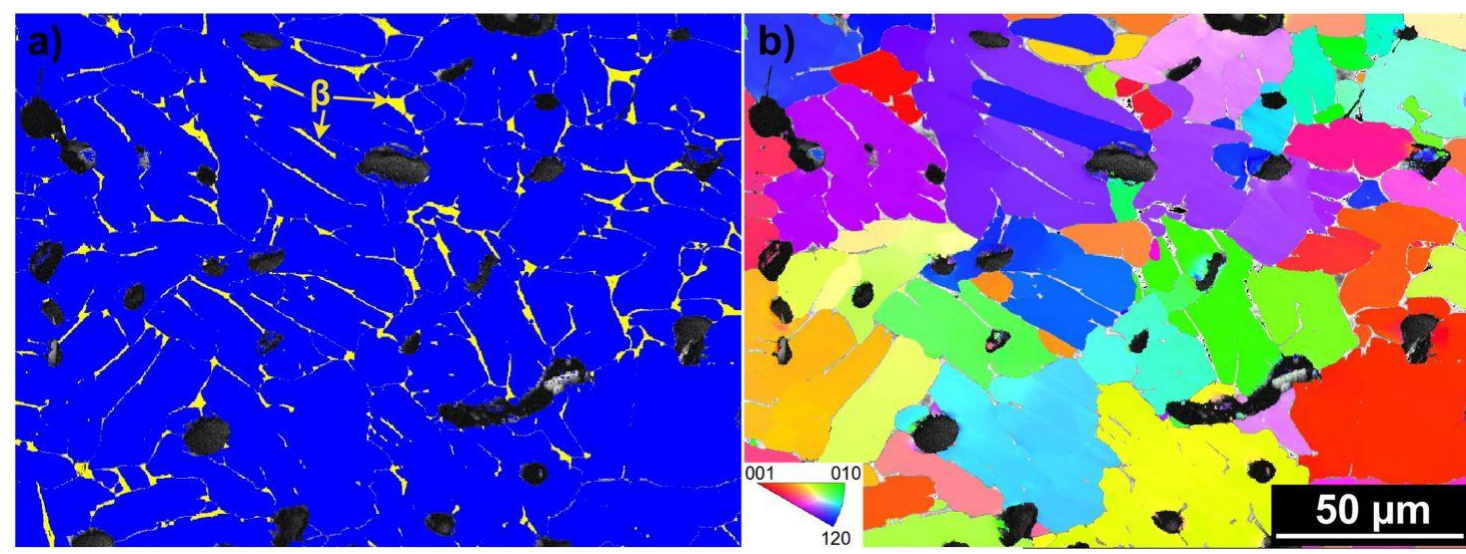

Figure 9: Final microstructure: (a) Map of crystallographic phases and (b) EBSD (IPF) map of a sintered sample. 
Figure 9 shows the microstructure obtained at the end of the whole process. Map of crystallographic phases (Figure 9 (a)), highlights the presence of the $\beta$ phase at grain boundaries that form unclosed lamellae (yellow phase). A $5^{\circ}$ grain boundary criterion applied on the $\alpha$ phase shows that $\alpha$ grains comprise several unclosed lamellae ((Figure 9 (b))). Quantitative analysis by EBSD led to a volume fraction of $\beta$ phase of $4.0 \%$, which is in agreement with XRD patterns. The mean grain size of the $\alpha$ grains was evaluated at $19 \mu \mathrm{m}$. This coarse but still lamellar microstructure is due to the low cooling rate applied during sintering: below $0.5^{\circ} \mathrm{C} \cdot \mathrm{s}^{-1}$ but above $0.1{ }^{\circ} \mathrm{C} \cdot \mathrm{s}^{-1}$. This as-sintered microstructure completely differs from finer microstructures obtained by powder bed fusion techniques. Indeed, the fast cooling rate induced by LBM process $\left(10^{5}-10^{6}{ }^{\circ} \mathrm{C} \cdot \mathrm{s}^{-1}\right)$ leads to a martensitic microstructure $[73,74]$. Also, even if the high chamber temperature used during EBM process allows the martensite transformation into $\alpha+\beta$ structure after solidification, the final microstructure reached by EBM presents fine Windmanstätten $\alpha$ laths [74,75].

\subsection{Mechanical properties}

The measured hardness, $(243 \pm 8) \mathrm{HV}_{0.5}$, is in accordance with commonly observed values on Ti64 samples with similar sintering density [70,76,77].

Two different conditions were used for the compressive tests: the first scaffold was printed shortly after taking the ink out of the fridge, whereas the two other scaffolds have been printed after reaching temperature equilibrium at $25^{\circ} \mathrm{C}$. The first case (below $25^{\circ} \mathrm{C}$ ) was used as a way to assess the robustness and limitations of the process by giving an overview of rheology impact on final properties. Stress-strain curves under compression are presented on Figure 10.

First it can be observed that stress-strain curve evolutions are really similar except for the stress drop on the blue curve representing the first scaffold (Figure 10 (a)). This drop in stress can be explained by the preferential densification of the last two printed layers, as shown on Figure 10 (d). This phenomenon highlights the importance of controlling temperature with precision when printing pluronic based ink. Indeed, a temperature a little bit too low can lead to a not stiff enough ink, thus to a compaction of the first printed layers under the weight of the following ones, inducing a density gradient between the top and the bottom of the sample. This leads to a preferential densification of the less dense layers under compressive load, before getting a more homogeneous densification.

Formation of vertical cracks were observed on samples surfaces, during the densification that follows the elastic domain. The first crack was formed for a 5-6\% strain and have been then followed by other cracks. X-Ray tomography performed during interrupted compression, and realised in this densification domain confirms that these cracks are only located in outer filaments (see Figure 10 (b) that shows one example of scan during densification domain). They are parallel to the loading direction and propagate only across one strut. At this stage, interfaces between layers seem sufficient to stop their propagation. Note also that their initiation does not lead to a stress drop or a plateau (Figure 10 (a)) as the stress continues to rise with increasing strain. The authors think this phenomenon is related to the ink/process combination, which leads to greater sagging of the external filaments than the internal ones.

This densification domain is followed by a plateau on the stress-strain curve that occurs when the scaffold is almost fully dense in the compression direction (Figure 10 (a) and (c)). According to Figure 10 (c), this plateau is due to the initiation of larger cracks that cross several struts at the same time and propagate at $45^{\circ}$ to the compression direction. At this stage, it can be considered that the sample failure is reached, even though no stress drop is observed yet.

Several results from these tests have to be noted. First, Young's modulus obtained with these structures $(28-30 \mathrm{GPa})$ is considerably lower than for dense Ti64 structures $(\sim 110 \mathrm{GPa})$, and sufficiently similar to bone modulus to avoid stress shielding (Table 5). Secondly, our scaffolds present a ductile behaviour with one of the highest specific mechanical strength among Ti64 3D printed porous structures (Table 5), even compared with other, well-established techniques such as EBM or SLM. Even if not detailed in this article, the debinding/sintering kinetics are of primary importance to optimise strength and ductility, and the absence of brittle carbides/oxides in sintered parts may explain the enhanced properties compared to Elsayed et al.. 
a)

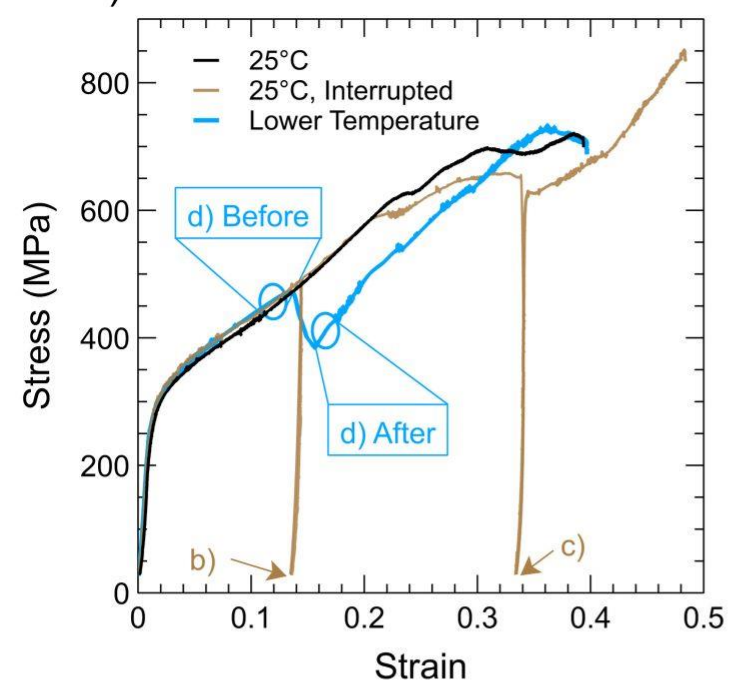

Strain

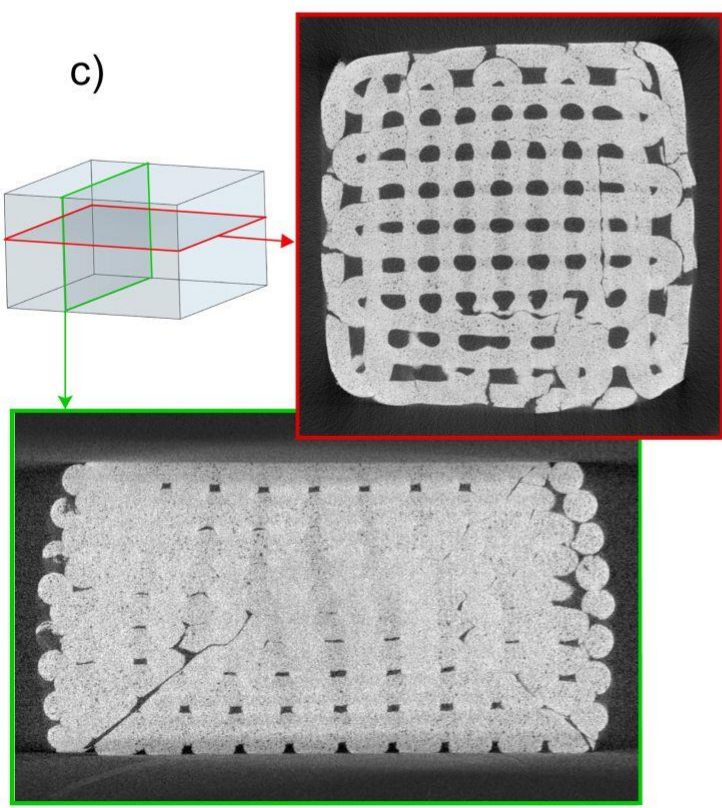

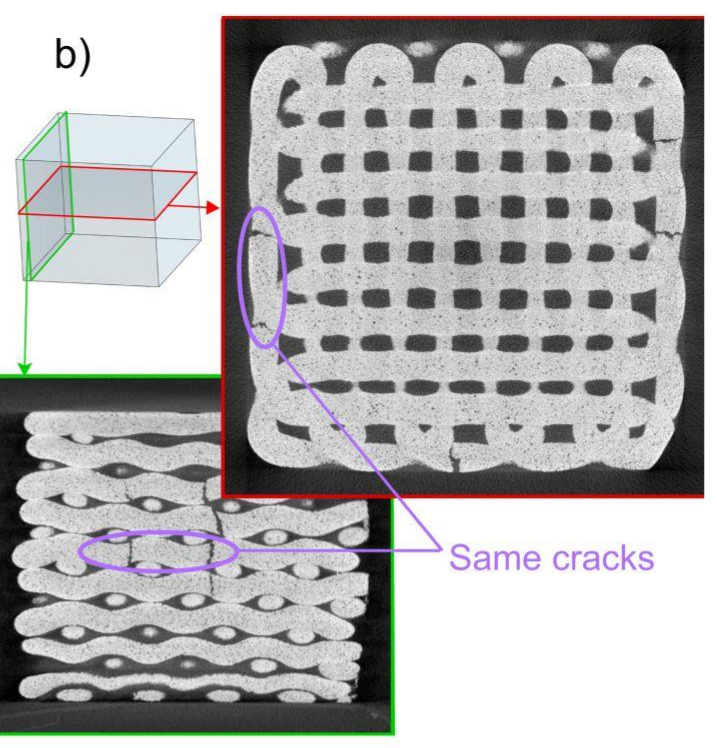

d)

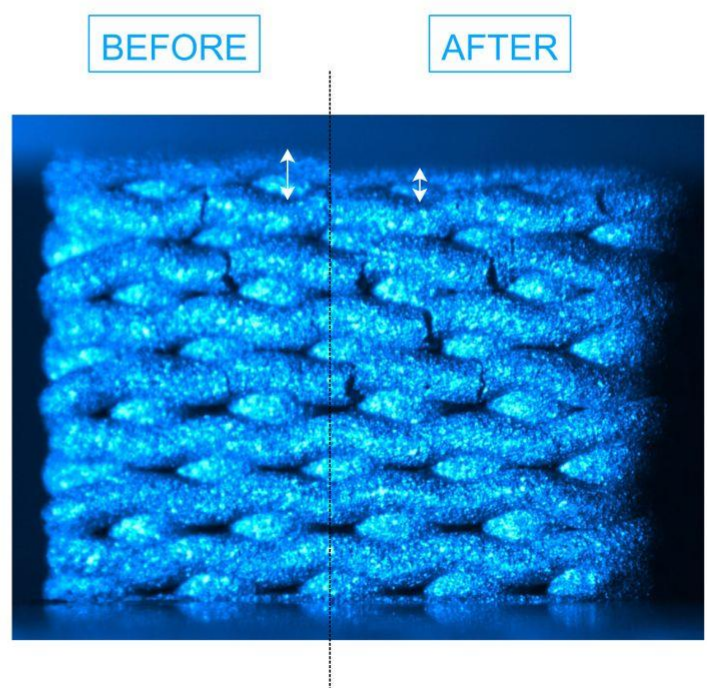

Figure 10 : Compressive tests: (a) Stress-strain curves obtained for the 3 samples printed with the P25T50 ink; (b) X-Ray tomographic sections showing only surficial cracks for a 14\% strain; (c) X-Ray tomographic sections showing internal cracks at 33\% strain; (d) Images registered by the camera before and after the stress drop.

Table 5 : Mechanical properties of divers Ti64 cellular structures in comparison to natural bone.

\begin{tabular}{|c|c|c|c|c|c|c|c|c|c|}
\hline & $\begin{array}{l}\text { Strut } \\
\text { size } \\
(\mu \mathrm{m})\end{array}$ & $\begin{array}{l}\text { Pore } \\
\text { size } \\
(\mu \mathrm{m})\end{array}$ & $\begin{array}{l}\text { Density } \\
\left(\mathrm{g} / \mathrm{cm}^{3}\right)\end{array}$ & $\begin{array}{c}\mathrm{E} \\
(G P a)\end{array}$ & $\begin{array}{c}\mathrm{E} / \rho \\
\left(\mathrm{GPa} . \mathrm{cm}^{3} / \mathrm{g}\right)\end{array}$ & $\begin{array}{r}\text { (or } \\
(N)\end{array}$ & $\begin{array}{l}S \\
U C S) \\
(P a)\end{array}$ & $\begin{array}{c} \\
\text { (or } \\
(M P \\
(M P\end{array}$ & $\begin{array}{l}S / \rho \\
(C S / \rho) \\
\left(\mathrm{cm}^{3} / \mathrm{g}\right)\end{array}$ \\
\hline$E B M[32]$ & 941 & 1020 & 2.18 & 3 & 1.4 & - & (160) & 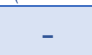 & (73) \\
\hline$E B M[32]$ & 466 & 765 & 2.22 & 0.6 & 0.3 & - & (7) & 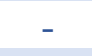 & (3) \\
\hline SLM [78] & 610 & 1428 & 1.60 & 8.7 & 5.5 & 170 & (219) & 106 & (137) \\
\hline$D I W[54]$ & 570 & 402 & 1.99 & 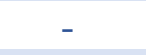 & - & - & (280) & - & (140) \\
\hline$D I W[53,56]$ & 685 & 320 & 2.09 & . & - & 120 & $(-)$ & 57 & $(-)$ \\
\hline$D I W[5656]$ & 708 & 697 & 1.83 & - & - & 125 & $(-)$ & 68 & $(-)$ \\
\hline$D I W[56]$ & 713 & 1492 & 1.42 & - & - & 120 & $(-)$ & 84 & $(-)$ \\
\hline This work & 710 & 350 & 2.52 & $28-30$ & 11.4 & 265 & (700) & 105 & (278) \\
\hline Bone [79] & - & - & $1.8-2.1$ & $3-20$ & $2-10$ & 130 & -180 & 70 & -100 \\
\hline
\end{tabular}


Increasing the porosity of the printed parts would lead to a better match of the stiffness of the scaffold with that of bone, while probably allowing to keep a higher yield strength than bone. To do so, adjusting strut size or interstrut distance are both possible. In the case of powder bed fusion technologies, an excessive down sizing of the constitutive struts may lead to drastic embrittlement caused by the microstructures induced by extreme cooling rates (Table 5). We expect a more moderate effect using direct-ink writing and subsequent sintering that involves lower cooling rate, independent of the strut size.

However, in a very recent paper Elsayed showed a significant microstructural change on small diameter struts $(250 \mu \mathrm{m})$, leading to lower mechanical properties [56]. This is believed to be related to the presence of large quantity of carbides, highlighting the importance of carbon diffusion on the mechanical properties. Thus a strut-size effect in robocast titanium may be related to chemical diffusion length rather than to heat diffusion as in SLM or EBM. This still remains to be explored in depth.

\subsection{Cells proliferation}

Characterisations of MG-63 cells proliferation by both PrestoBlue technique and SEM imaging are presented on Figure 11. This proliferation test can be validated by significant cell proliferation on both types of controls (plastic and Ti64).

Figure 11 (a) shows that no cytotoxicity is observed. Proliferation is observed for all materials. It is similar for the Ti64 reference and the plastic reference and seems lower for the Ti64 scaffolds. However, SEM observations show that, at day 6, the cells form a continuous mat on the scaffold (they have reached confluence) but remain isolated on Ti64 reference, which may seem contradictory with the quantification of proliferation shown on Figure 11 (a). This is probably due to an artefact of the measurement of cell proliferation by the PrestoBlue technique. Indeed it is confirmed that the cells can indeed slip and adhere inside the pores left by sintering, as shown in Figure 11(b). But diffusion of reasazurin and resafurin is not guaranteed inside the small pores of the structures, making the detection of cells inside these pores very difficult.

In addition, cells are well spread out and flat on the surfaces of scaffolds, synonymous with proper adhesion, while they are more rounded on the surface of the Ti64 references. This is due to the difference in roughness that enhances cell adhesion [80,81], the Ti64 reference being the smoothest sample. 


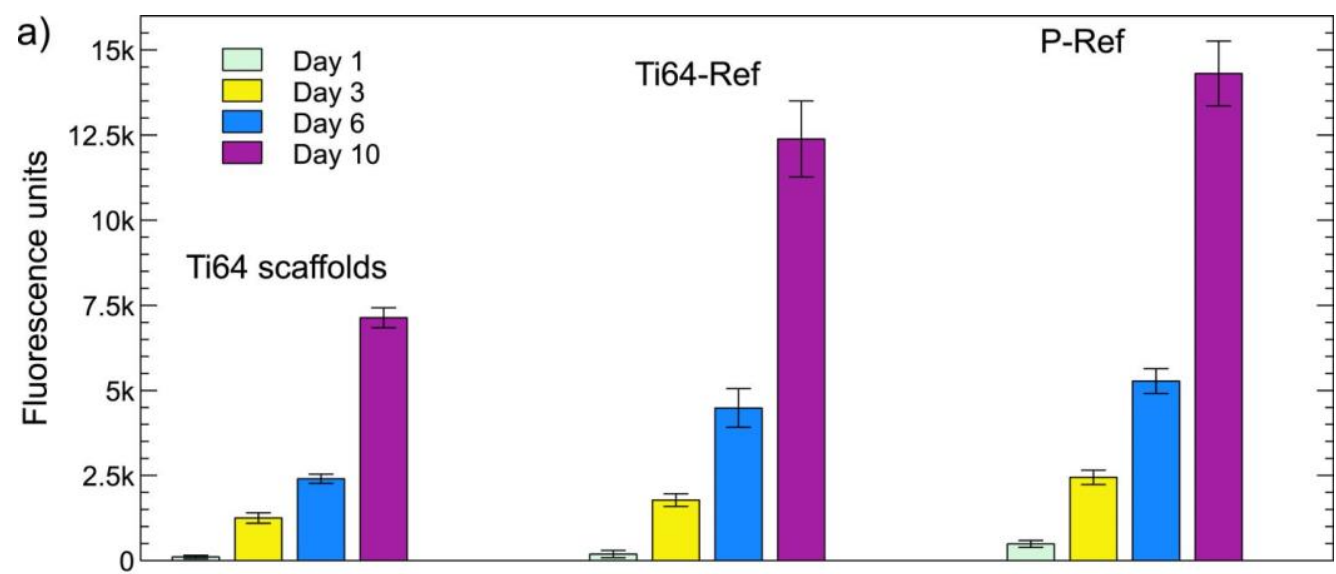

b) Scaffold, Day 6 ?
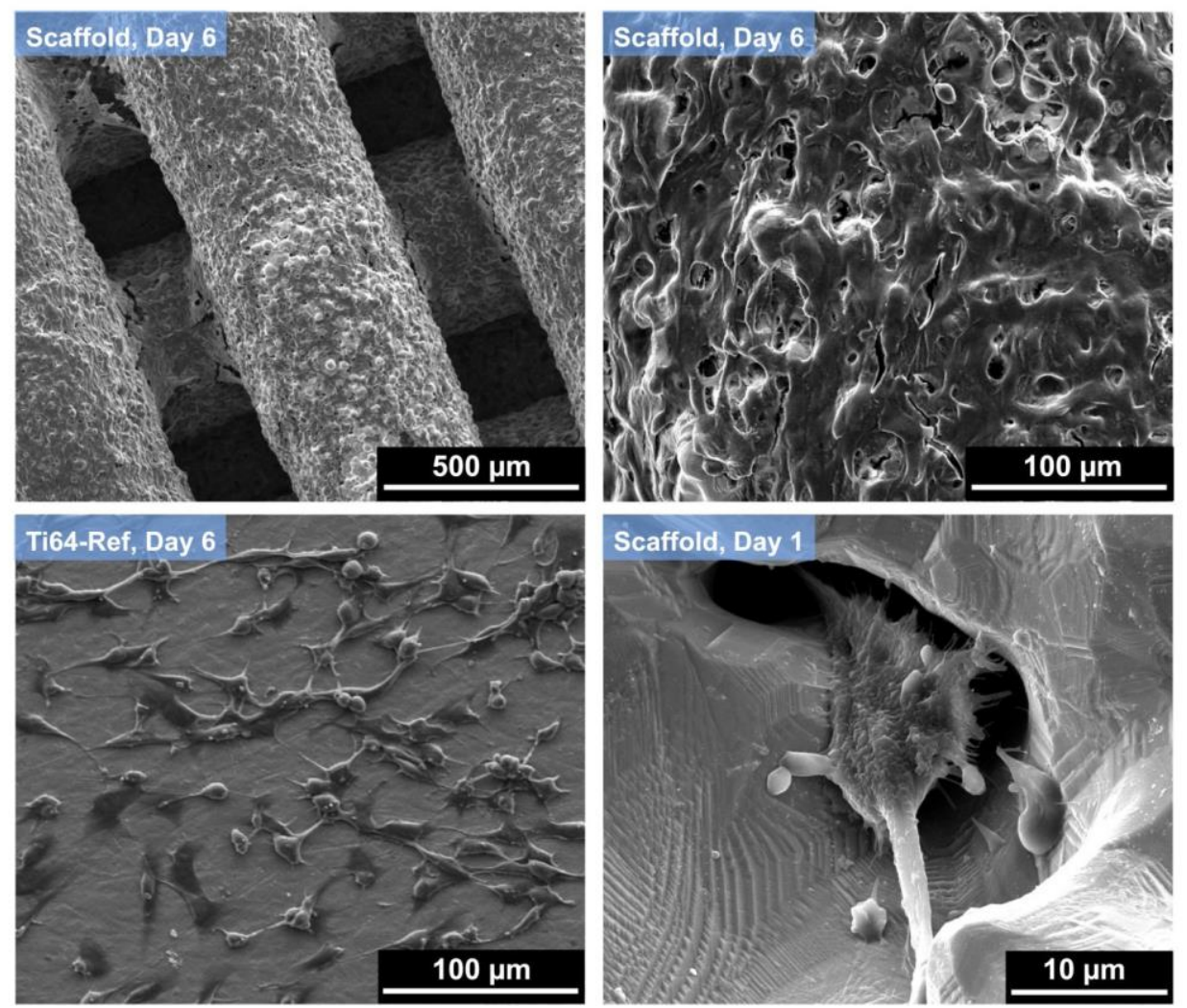

Figure 11: Cell proliferation: (a) Fluorescence measured with the PrestoBlue technique after the different incubation times; (b) SEM images showing the spreading of MG-63 cells on the surface of Ti64 samples. Cells can be found within scaffold micropores.

\section{Conclusion}

- A 25 wt\% Pluronic F-127 hydrogel loaded with 50 vol\% of Ti64 particles can be used to print scaffold structure using low-cost 3D printers as robocasting. Printing with this ink leads to dimensional deviations from the CAD file of less than $10 \%$ of the strut diameter, which can be considered as optimised for DIW of metals (using design and printing parameters presented in this study).

- A partial sintering of $2 \mathrm{~h}$ at $1200{ }^{\circ} \mathrm{C}$ enables to keep an interconnected network of micronic pores within struts, which is promising for osseoconduction.

- These Ti64 foams exhibit outstanding strength and ductility when compared to scaffolds with similar porosity previously manufactured by either DIW or powder bed fusion technologies, which is promising for load-bearing bone implants.

- The preliminary biological tests show a good proliferation of osteoblast-like cells, which also reach confluence faster on the porous scaffold than on the smooth and dense controls. 


\section{CRediT authorship contribution statement}

M.Coffigniez: Investigation, Visualisation, Writing - Original Draft. L.Gremillard: Conceptualisation, Supervision, Writing - Review \& Editing. J.Lachambre: Methodology \& Software for the discrepancy from CAD file. J.Adrien: X-Ray computed tomography acquisition, images analysis. S.Balvay: Cell culture, cell proliferation measurements and imaging. X.Boulnat: Conceptualisation, Supervision, Writing - Review \& Editing.

Declaration of Competing Interest

The authors declare that they have no known competing financial interests or personal relationships that could have appeared to influence the work reported in this paper.

Acknowledgements

The authors would like to thank S. Simon and C. Rigollet for their precious help on the thermogravimetric analysis.

\section{REFERENCES}

1. B.V. Krishna, S. Bose, A. Bandyopadhyay, Low stiffness porous Ti structures for load-bearing implants, Acta Biomaterialia, 3 (6) (2007), pp. 997-1006, 10.1016/j.actbio.2007.03.008

2. Q. Chen, G.A. Thouas, Metallic implant biomaterials, Materials Science and Engineering: R: Reports, 87 (2015), pp. 1-57, 10.1016/j.mser.2014.10.001

3. F. Guillemot, Recent advances in the design of titanium alloys for orthopedic applications, Expert Review of Medical Devices, 2 (6) (2005), pp. 741-748, 10.1586/17434440.2.6.741

4. A.H. Glassman, J.D. Bobyn, M. Tanzer, New Femoral Designs: Do They Influence Stress Shielding? A Publication of The Association of Bone and Joint Surgeons® । CORR®, 453 (2006), pp. 64-74, $\underline{10.1097 / 01 . b l o .0000246541 .41951 .20}$

5. S. Guizzardi, C. Galli, D. Martini, S. Belletti, A. Tinti, M. Raspanti, P. Taddei, A. Ruggeri, R. Scandroglio, Different Titanium Surface Treatment Influences Human Mandibular Osteoblast Response, Journal of Periodontology, 75 (2) (2004), pp. 273-282, 10.1902/jop.2004.75.2.273

6. K. Anselme, M. Bigerelle, Statistical demonstration of the relative effect of surface chemistry and roughness on human osteoblast short-term adhesion, Journal of Materials Science: Materials in Medicine, 17 (5) (2006), pp. 471-479, 10.1007/s10856-006-8475-8

7. S.P. Xavier, P.S. Carvalho, M.M. Beloti, A.L. Rosa, Response of rat bone marrow cells to commercially pure titanium submitted to different surface treatments, Journal of Dentistry, 31 (3) (2003), pp. 173-180, 10.1016/S0300-5712(03)00027-7

8. F. Lüthen, R. Lange, P. Becker, J. Rychly, U. Beck, J.B. Nebe, The influence of surface roughness of titanium on $\beta$ 1- and $\beta 3$-integrin adhesion and the organization of fibronectin in human osteoblastic cells, Biomaterials, 26 (15) (2005), pp. 2423-2440, 10.1016/j.biomaterials.2004.07.054

9. E. Sandrini, C. Giordano, V. Busini, E. Signorelli, A. Cigada, Apatite formation and cellular response of a novel bioactive titanium, Journal of Materials Science: Materials in Medicine, 18 (6) (2007), pp. 1225$1237,10.1007 / \mathrm{s} 10856-007-0122-5$

10. G. Zhao, O. Zinger, Z. Schwartz, M. Wieland, D. Landolt, B.D. Boyan, Osteoblast-like cells are sensitive to submicron-scale surface structure, Clinical Oral Implants Research, 17 (3) (2006), pp. 258-264, 10.1111/j.1600-0501.2005.01195.x

11. K. Das, S. Bose, A. Bandyopadhyay, Surface modifications and cell-materials interactions with anodized Ti, Acta Biomaterialia, 3 (4) (2007), pp. 573-585, 10.1016/j.actbio.2006.12.003

12. S.N. Nayab, F.H. Jones, I. Olsen, Effects of calcium ion implantation on human bone cell interaction with titanium, Biomaterials, 26 (23) (2005), pp. 4717-4727, 10.1016/j.biomaterials.2004.11.044

13. D. Krupa, J. Baszkiewicz, B. Rajchel, A. Barcz, J. Sobczak, A. Biliński, T. Borowski, Effect of calciumion implantation on the corrosion resistance and bioactivity of the Ti6Al4V alloy, Vacuum, 81 (10) (2007), pp. 1310-1313, 10.1016/j.vacuum.2007.01.035

14. S.D. Cook, K.A. Thomas, J.F. Kay, M. Jarcho, Hydroxyapatite-Coated Titanium for Orthopedic Implant Applications, Clinical Orthopaedics and Related Research (232) (1988), pp. 225-243, 10.1097/00003086$\underline{198807000-00030}$ 
15. C. García, S. Ceré, A. Durán, Bioactive coatings deposited on titanium alloys, Journal of Non-Crystalline Solids, 352 (32-35) (2006), pp. 3488-3495, 10.1016/j.jnoncrysol.2006.02.110

16. K. Kuroda, M. Okido, Hydroxyapatite Coating of Titanium Implants Using Hydroprocessing and Evaluation of Their Osteoconductivity, Bioinorganic Chemistry and Applications, 2012 (2012), pp. 1-7, $10.1155 / 2012 / 730693$

17. L. Peddi, R.K. Brow, R.F. Brown, Bioactive borate glass coatings for titanium alloys, Journal of Materials Science: Materials in Medicine, 19 (9) (2008), pp. 3145-3152, 10.1007/s10856-008-3419-0

18. X. Liu, S. Tao, C. Ding, Bioactivity of plasma sprayed dicalcium silicate coatings, Biomaterials, 23 (3) (2002), pp. 963-968, 10.1016/S0142-9612(01)00210-1

19. L. Biasetto, R. Bertolini, H. Elsayed, A. Ghiotti, S. Bruschi, Use of cryogenic machining to improve the adhesion of sphene bioceramic coatings on titanium substrates for dental and orthopaedic applications, Ceramics International, 45 (5) (2019), pp. 5941-5951, 10.1016/j.ceramint.2018.12.063

20. S. Piscanec, L. ColombiCiacchi, E. Vesselli, G. Comelli, O. Sbaizero, S. Meriani, A. De Vita, Bioactivity of TiN-coated titanium implants, Acta Materialia, 52 (5) (2004), pp. 1237-1245, 10.1016/j.actamat.2003.11.020

21. S. Rammelt, T. Illert, S. Bierbaum, D. Scharnweber, H. Zwipp, W. Schneiders, Coating of titanium implants with collagen, RGD peptide and chondroitin sulfate, Biomaterials, 27 (32) (2006), pp. 55615571, 10.1016/j.biomaterials.2006.06.034

22. B. Marquardt, R. Shetty, Beta Titanium Alloy Processed for High Strength Orthopedic Applications, Titanium, Niobium, Zirconium, and Tantalum for Medical and Surgical Applications (Jan. 2006), 10.1520/STP37548S

23. G. Ryan, A. Pandit, D.P. Apatsidis, Fabrication methods of porous metals for use in orthopaedic applications, Biomaterials, 27 (13) (2006), pp. 2651-2670, 10.1016/j.biomaterials.2005.12.002

24. J.C. Li, D.C. Dunand, Mechanical properties of directionally freeze-cast titanium foams, Acta Materialia, 59 (1) (2011), pp. 146-158, 10.1016/j.actamat.2010.09.019

25. L. Biasetto, E.G. de Moraes, P. Colombo, F. Bonollo, Ovalbumin as foaming agent for Ti6Al4V foams produced by gelcasting, Journal of Alloys and Compounds, 687 (2016), pp. 839-844, 10.1016/j.jallcom.2016.06.218

26. W. Niu, C. Bai, G. Qiu, Q. Wang, Processing and properties of porous titanium using space holder technique, Materials Science and Engineering: A, 506 (1) (2009), pp. 148-151, 10.1016/j.msea.2008.11.022

27. M. Sharma, G.K. Gupta, O.P. Modi, B.K. Prasad, A.K. Gupta, Titanium foam through powder metallurgy route using acicular urea particles as space holder, Materials Letters, 65 (21) (2011), pp. 3199-3201, 10.1016/j.matlet.2011.07.004

28. N. Jha, D.P. Mondal, J. DuttaMajumdar, A. Badkul, A.K. Jha, A.K. Khare, Highly porous open cell Tifoam using $\mathrm{NaCl}$ as temporary space holder through powder metallurgy route, Materials \& Design, 47 (2013), pp. 810-819, 10.1016/j.matdes.2013.01.005

29. M. de Wild, S. Zimmermann, J. Rüegg, R. Schumacher, T. Fleischmann, C. Ghayor, F.E.Weber, Influence of Microarchitecture on Osteoconduction and Mechanics of Porous Titanium Scaffolds Generated by Selective Laser Melting, 3D Printing and Additive Manufacturing, 3 (3) (2016), pp. 142-151, $10.1089 / 3 \mathrm{dp} .2016 .0004$

30. I. Eldesouky, O. Harrysson, H. West, H. Elhofy, Electron beam melted scaffolds for orthopedic applications, Additive Manufacturing, 17 (2017), pp. 169-175, 10.1016/j.addma.2017.08.005

31. H. Hassanin, L. Finet, S.C. Cox, P. Jamshidi, L.M. Grover, D.E. Shepherd, O. Addison, M.M. Attallah, Tailoring selective laser melting process for titanium drug-delivering implants with releasing microchannels, Additive Manufacturing, 20 (2018), pp. 144-155, 10.1016/j.addma.2018.01.005

32. J. Parthasarathy, B. Starly, S. Raman, A. Christensen, Mechanical evaluation of porous titanium (Ti6Al4V) structures with electron beam melting (EBM), Journal of the Mechanical Behavior of Biomedical Materials, 3 (3) (2010), pp. 249-259, 10.1016/j.jmbbm.2009.10.006

33. H.A. Zaharin, A.M. AbdulRani, F.I. Azam, T.L. Ginta, N. Sallih, A. Ahmad, N.A. Yunus, T.Z.A. Zulkifli, Effect of Unit Cell Type and Pore Size on Porosity and Mechanical Behavior of Additively Manufactured Ti6Al4V Scaffolds, Materials, 11 (12) (2018), p. 2402, 10.3390/ma11122402

34. V. Karageorgiou, D. Kaplan, Porosity of 3 D biomaterial scaffolds and osteogenesis, Biomaterials, 26 (27) (2005), pp. 5474-5491, 10.1016/j.biomaterials.2005.02.002

35. S.K. Lan Levengood, S.J. Polak, M.B. Wheeler, A.J. Maki, S.G. Clark, R.D. Jamison, A.J. Wagoner Johnson, Multiscale osteointegration as a new paradigm for the design of calcium phosphate scaffolds for bone regeneration, Biomaterials, 31 (13) (2010), pp. 3552-3563, 10.1016/j.biomaterials.2010.01.052 
36. S.J. Polak, L.E. Rustom, G.M. Genin, M. Talcott, A.J. Wagoner Johnson, A mechanism for effective cellseeding in rigid, microporous substrates, Acta Biomaterialia, 9 (8) (2013), pp. 7977-7986, 10.1016/j.actbio.2013.04.040

37. F. O'Brien, B. Harley, I. Yannas, L. Gibson, The effect of pore size on cell adhesion in collagen-GAG scaffolds, Biomaterials, 26 (4) (2005), pp. 433-441, 10.1016/j.biomaterials.2004.02.052

38. K.A. Hing, B. Annaz, S. Saeed, P.A. Revell, T. Buckland, Microporosity enhances bioactivity of synthetic bone graft substitutes, Journal of Materials Science. Materials in Medicine, 16 (5) (2005), pp. 467-475, 10.1007/s10856-005-6988-1

39. O. Chan, M.J. Coathup, A. Nesbitt, C.Y. Ho, K.A. Hing, T. Buckland, C. Campion, G.W. Blunn, The effects of microporosity on osteoinduction of calcium phosphate bone graft substitute biomaterials, Acta Biomaterialia, 8 (7) (2012), pp. 2788-2794, 10.1016/j.actbio.2012.03.038

40. M. Bohner, G. Baroud, A. Bernstein, N. Döbelin, L. Galea, B. Hesse, R. Heuberger, S. Meille, P. Michel, B. vonRechenberg, J. Sague, H. Seeherman, Characterization and distribution of mechanically competent mineralized tissue in micropores of $\beta$-tricalcium phosphate bone substitutes, Materials Today, 20 (3) (2017), pp. 106-115, 10.1016/j.mattod.2017.02.002

41. J.I. Cesarano, T. Baer, P. Calvert, Recent developments in freeform fabrication of dense ceramics from slurry deposition, Tech. Rep. SAND-97-2857C, CONF-970888-, 554831 (1997). 10.2172/554831.

42. J.E. Smay, J. Cesarano, J.A. Lewis, Colloidal Inks for Directed Assembly of 3-D Periodic Structures, Langmuir, 18 (14) (2002), pp. 5429-5437, 10.1021/la0257135

43. J.A. Lewis, Direct Ink Writing of 3D Functional Materials, Advanced Functional Materials, 16 (17) (2006), pp. 2193-2204, 10.1002/adfm.200600434

44. B.Y. Ahn, D. Shoji, C.J. Hansen, E. Hong, D.C. Dunand, J.A. Lewis, Printed Origami Structures, Advanced Materials, 22 (20) (2010), pp. 2251-2254, 10.1002/adma.200904232

45. J. Franco, P. Hunger, M. Launey, A. Tomsia, E. Saiz, Direct write assembly of calcium phosphate scaffolds using a water-based hydrogel, Acta Biomaterialia, 6 (1) (2010), pp. 218-228, 10.1016/j.actbio.2009.06.031

46. Q. Fu, E. Saiz, A.P. Tomsia, Direct ink writing of highly porous and strong glass scaffolds for loadbearing bone defects repair and regeneration, Acta Biomaterialia, 7 (10) (2011), pp. 3547-3554, 10.1016/j.actbio.2011.06.030

47. E. Feilden, E.G.-T. Blanca, F. Giuliani, E. Saiz, L. Vandeperre, Robocasting of structural ceramic parts with hydrogel inks, Journal of the European Ceramic Society, 36 (10) (2016), pp. 2525-2533, 10.1016/j.jeurceramsoc.2016.03.001

48. C. Petit, S. Meille, E. Maire, L. Gremillard, J. Adrien, G.Y. Lau, A.P. Tomsia, Fracture behavior of robocast $H A / \beta$-TCP scaffolds studied by X-ray tomography and finite element modeling, Journal of the European Ceramic Society, 37 (4) (2017), pp. 1735-1745, 10.1016/j.jeurceramsoc.2016.11.035

49. A. Nommeots-Nomm, P.D. Lee, J.R. Jones, Direct ink writing of highly bioactive glasses, Journal of the European Ceramic Society, 38 (3) (2018), pp. 837-844, 10.1016/j.jeurceramsoc.2017.08.006

50. J.P. Li, J.R. de Wijn, C.A. Van Blitterswijk, K. de Groot, Porous Ti6Al4V scaffold directly fabricating by rapid prototyping: Preparation and in vitro experiment, Biomaterials, 27 (8) (2006), pp. 1223-1235, 10.1016/j.biomaterials.2005.08.033

51. A.E. Jakus, S.L. Taylor, N.R. Geisendorfer, D.C. Dunand, R.N. Shah, Metallic Architectures from 3DPrinted Powder-Based Liquid Inks, Advanced Functional Materials, 25 (45) (2015), pp. 6985-6995, 10.1002/adfm.201503921

52. M. YetnaN'Jock, E. Camposilvan, L. Gremillard, E. Maire, D. Fabrègue, D. Chicot, K. Tabalaiev, J. Adrien, Characterization of 100Cr6 lattice structures produced by robocasting, Materials \& Design, 121 (2017), pp. 345-354, 10.1016/j.matdes.2017.02.066

53. H. Elsayed, P. Rebesan, G. Giacomello, M. Pasetto, C. Gardin, L. Ferroni, B. Zavan, L. Biasetto, Direct ink writing of porous titanium (Ti6Al4V) lattice structures, Materials Science and Engineering: C, 103 (2019), Article 109794, 10.1016/j.msec.2019.109794

54. J.P. Li, J.R. de Wijn, C.A. van Blitterswijk, K. de. Groot, Porous Ti6Al4V scaffolds directly fabricated by 3D fibre deposition technique: Effect of nozzle diameter, Journal of Materials Science: Materials in Medicine, 16 (12) (2005), pp. 1159-1163, 10.1007/s10856-005-4723-6

55. Y. Chen, P. Han, L.-J. Vandi, A. Dehghan-Manshadi, J. Humphry, D. Kent, I. Stefani, P. Lee, M. Heitzmann, J. Cooper-White, M. Dargusch, A biocompatible thermoset polymer binder for Direct Ink Writing of porous titanium scaffolds for bone tissue engineering, Materials Science and Engineering: C, 95 (2019), pp. 160-165, 10.1016/j.msec.2018.10.033 
56. H. Elsayed, N. Novak, M. Vesenjak, F. Zanini, S. Carmignato, L. Biasetto, The effect of strut size on microstructure and compressive strength of porous Ti6Al4V lattices printed via Direct Ink Writing, Materials Science and Engineering: A, 787 (2020), Article 139484, 10.1016/j.msea.2020.139484

57. A. M'Barki, L. Bocquet, A. Stevenson, Linking Rheology and Printability for Dense and Strong Ceramics by Direct Ink Writing, Scientific Reports, 7 (1) (Dec. 2017), 10.1038/s41598-017-06115-0

58. E. Gioffredi, M. Boffito, S. Calzone, S.M. Giannitelli, A. Rainer, M. Trombetta, P. Mozetic, V. Chiono, Pluronic F127 Hydrogel Characterization and Biofabrication in Cellularized Constructs for Tissue Engineering Applications, Procedia CIRP, 49 (2016), pp. 125-132, 10.1016/j.procir.2015.11.001

59. E. Feilden, C. Ferraro, Q. Zhang, E. García-Tuñón, E. DaElia, F. Giuliani, L. Vandeperre, E. Saiz, 3D Printing Bioinspired Ceramic Composites, Scientific Reports, 7 (1) (Dec. 2017), 10.1038/s41598-01714236-9

60. R. Landers, A. Pfister, U. Hübner, H. John, R. Schmelzeisen, R. Mülhaupt, Fabrication of soft tissue engineering scaffolds by means of rapid prototyping techniques, Journal of Materials Science, 37 (2002), pp. 3107-3116.

61. W.S. Janna, Introduction to Fluid Mechanics (Sixth Edition), CRC Press (2020)

62. J. Schindelin, I. Arganda-Carreras, E. Frise, V. Kaynig, M. Longair, T. Pietzsch, S. Preibisch, C. Rueden, S. Saalfeld, B. Schmid, J.-Y. Tinevez, D.J. White, V. Hartenstein, K. Eliceiri, P. Tomancak, A. Cardona, Fiji: An open-source platform for biological-image analysis, Nature Methods, 9 (7) (2012), pp. 676-682, 10.1038/nmeth.2019

63. M.F. Ashby, A.G. Evans, N.A. Fleck, L.J. Gibson, J.W. Hutchinson, H.N.G. Wadley, Metal Foams: A Design Guide (2000), p. 263

64. W.H. Herschel, R. Bulkley, Konsistenzmessungen von Gummi-Benzollösungen, Kolloid-Zeitschrift, 39 (4) (1926), pp. 291-300, 10.1007/BF01432034

65. L.V. Woodcock, Percolation transitions in the hard-sphere fluid, AIChE Journal, 58 (5) (2012), pp. 1610$1618,10.1002 /$ aic. 12666

66. I.Zuriguel, Invited review : Clogging of granular materials in bottlenecks, arXiv :1412.5806, Papers in Physics, 6 (0) (2014), Article 060014, 10.4279/PIP.060014

67. D. Gella, D. Maza, I. Zuriguel, A. Ashour, R. Arévalo, R. Stannarius, Linking bottleneck clogging with flow kinematics in granular materials: The role of silo width, Physical Review Fluids, 2 (8) (2017), Article 084304, 10.1103/PhysRevFluids.2.084304

68. A. Janda, I. Zuriguel, A. Garcimartín, D. Maza, Clogging of granular materials in narrow vertical pipes discharged at constant velocity, Granular Matter, 17 (5) (2015), pp. 545-551, 10.1007/s10035-015-0583$\underline{\mathrm{Z}}$

69. M. Qian, Y.F. Yang, S.D. Luo, H.P. Tang, 12 - Pressureless sintering of titanium and titanium alloys: Sintering densification and solute homogenization, M. Qian, F.H. (Sam)Froes (Eds.), Titanium Powder Metallurgy, Butterworth-Heinemann, Boston (2015), pp. 201-218, 10.1016/B978-0-12-800054-0.00012$\underline{5}$

70. J. Chávez, L. Olmos, O. Jiménez, D. Bouvard, E. Rodríguez, M. Flores, Sintering behaviour and mechanical characterisation of Ti64/xTiN composites and bilayer components, Powder Metallurgy, 60 (4) (2017), pp. 257-266, 10.1080/00325899.2017.1280585

71. T. Ebel, Metal injection molding (MIM) of titanium and titanium alloys, Handbook of Metal Injection Molding, Elsevier (2012), pp. 415-445, 10.1533/9780857096234.4.415

72. S. Malinov, W. Sha, Z. Guo, C. Tang, A. Long, Synchrotron X-ray diffraction study of the phase transformations in titanium alloys, Materials Characterization, 48 (4) (2002), pp. 279-295, 10.1016/S1044-5803(02)00286-3

73. R. Wauthle, B. Vrancken, B. Beynaerts, K. Jorissen, J. Schrooten, J.-P. Kruth, J. Van Humbeeck, Effects of build orientation and heat treatment on the microstructure and mechanical properties of selective laser melted Ti6Al4V lattice structures, Additive Manufacturing, 5 (2015), pp. 77-84, 10.1016/j.addma.2014.12.008

74. X. Zhao, S. Li, M. Zhang, Y. Liu, T.B. Sercombe, S. Wang, Y. Hao, R. Yang, L.E. Murr, Comparison of the microstructures and mechanical properties of Ti-6Al-4V fabricated by selective laser melting and electron beam melting, Materials \& Design, 95 (2016), pp. 21-31, 10.1016/j.matdes.2015.12.135

75. H. Galarraga, R.J. Warren, D.A. Lados, R.R. Dehoff, M.M. Kirka, P. Nandwana, Effects of heat treatments on microstructure and properties of Ti-6Al-4V ELI alloy fabricated by electron beam melting (EBM), Materials Science and Engineering: A, 685 (2017), pp. 417-428, 10.1016/j.msea.2017.01.019 
76. B. Song, S. Dong, H. Liao, C. Coddet, Process parameter selection for selective laser melting of Ti6Al4V based on temperature distribution simulation and experimental sintering, The International Journal of Advanced Manufacturing Technology, 61 (9-12) (2012), pp. 967-974, 10.1007/s00170-011-3776-6

77. J.-M. Oh, K.-H. Heo, W.-B. Kim, G.-S. Choi, J.-W. Lim, Sintering properties of Ti-6Al-4V alloys prepared using $\mathrm{Ti}_{\mathrm{TiH}}$ powders, Materials transactions, 54 (1) (2013), pp. 119-121, 10.2320/matertrans.M2012304

78. E. Sallica-Leva, A. Jardini, J. Fogagnolo, Microstructure and mechanical behavior of porous Ti-6Al-4V parts obtained by selective laser melting, Journal of the Mechanical Behavior of Biomedical Materials, 26 (2013), pp. 98-108, 10.1016/j.jmbbm.2013.05.011

79. L.J. Gibson, M.F. AshbyCellular Solids: Structure and Properties, Cambridge University Press (1999)

80. B. Nebe, F. Lüthen, R. Lange, P. Becker, U. Beck, J. Rychly, Topography-induced alterations in adhesion structures affect mineralization in human osteoblasts on titanium, Materials Science and Engineering: C, 24 (5) (2004), pp. 619-624, 10.1016/j.msec.2004.08.034

81. D. Docheva, D. Padula, C. Popov, W. Mutschler, H. Clausen-Schaumann, M. Schieker, Researching into the cellular shape, volume and elasticity of mesenchymal stem cells, osteoblasts and osteosarcoma cells by atomic force microscopy, Journal of Cellular and Molecular Medicine, 12 (2) (2008), pp. 537-552, $\underline{10.1111 / \mathrm{j} .1582-4934.2007 .00138 . \mathrm{x}}$ 